\title{
Idaho National Laboratory - Quarterly Performance Analysis
}

Lisbeth Mitchell

September 01, 2014

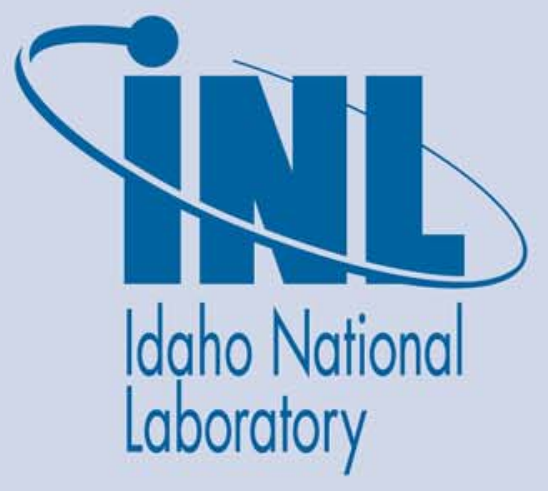

The INL is a U.S. Department of Energy National Laboratory operated by Battelle Energy Alliance 


\title{
Idaho National Laboratory Quarterly Performance Analysis
}

\author{
Lisbeth Mitchell
}

September 2014

\section{Idaho National Laboratory \\ Idaho Falls, Idaho 83415}

http://www.inl.gov

\author{
Prepared for the \\ U.S. Department of Energy \\ Office of Nuclear Energy \\ Under DOE Idaho Operations Office \\ Contract DE-AC07-05ID14517
}




\section{IDAHO NATIONAL}

LABORATORY

\section{QUARTERLY PERFORMANCE ANALYSIS}




\section{DISCLAIMER}

This information was prepared as an account of work sponsored by an agency of the U.S. Government. Neither the U.S. Government nor any agency thereof, nor any of their employees, makes any warranty, expressed

or implied, or assumes any legal liability or responsibility for the accuracy, completeness, or usefulness, of any information, apparatus, product, or process disclosed, or represents that its use would not infringe privately owned rights. References herein to any specific commercial product, process, or service by trade name, trade mark, manufacturer, or otherwise, does not necessarily constitute or imply its endorsement, recommendation, or favoring by the U.S. Government or any agency thereof. The views and opinions of authors expressed herein do not necessarily state or reflect those of the U.S. Government or any agency thereof. 


\section{Contents}

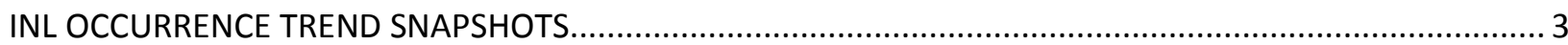

$4^{\text {th }}$ Qtr FY-14 KEY LESSONS LEARNED ISSUED BY INL ORGANIZATIONS .................................... 4

$4^{\text {th }}$ Qtr FY-14 ANALYSIS OF PERFORMANCE COMPARED TO OTHER COMPLEX REPORTING ....... 7

$4^{\text {th }}$ Qtr FY-14 GROUP 1 - OPERATIONAL EMERGENCIES ....................................................... 7

$4^{\text {th }}$ Qtr FY-14 GROUP 2 - PERSONNEL SAFETY AND HEALTH .............................................. 8

$4^{\text {th }}$ Qtr FY-14 GROUP 3 - NUCLEAR SAFETY BASIS EVENTS................................................. 13

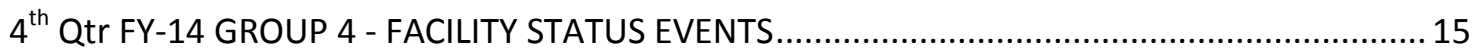

$4^{\text {th }}$ Qtr FY-14 GROUP 5 - ENVIRONMENTAL EVENTS......................................................... 18

$4^{\text {th }}$ Qtr FY-14 GROUP 6 - CONTAMINATION/RADIATION CONTROL EVENTS ............................. 19

$4^{\text {th }}$ Qtr FY-14 GROUP 7 - NUCLEAR EXPLOSIVE SAFETY EVENTS............................................ 20

$4^{\text {th }}$ Qtr FY-14 GROUP 8 - PACKAGING AND TRANSPORTATION EVENTS ................................... 20

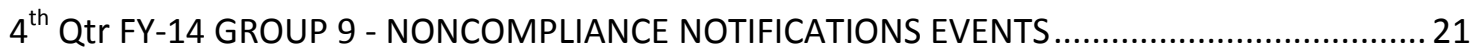

$3^{\text {rd }}$ Qtr FY-14 GROUP 10 - MANAGEMENT CONCERNS AND ISSUES ..................................... 22

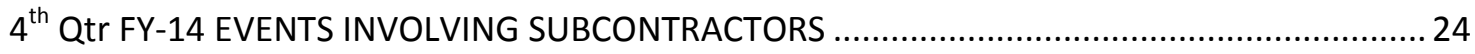

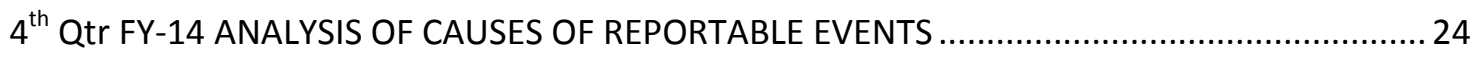

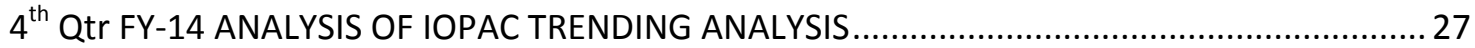


INL/EXT-14-33707

FY-14 $4^{\text {th }}$ Quarter

This report is published quarterly by the Idaho National Laboratory (INL) Quality and Performance Management Organization.

The Department of Energy (DOE) Occurrence Reporting and Processing System (ORPS), as prescribed in DOE Order 232.2,

"Occurrence Reporting and Processing of Operations

Information," requires a quarterly analysis of events, both reportable and not reportable, for the previous 12 months.

This report is the analysis of 60 reportable events (23 from the $4^{\text {th }}$ Qtr FY14 and 37 from the prior three reporting quarters), as well as 58 other issue reports (including not reportable events and Significant Category A and B conditions) identified at INL from July 2013 through October 2014.

Battelle Energy Alliance (BEA) operates the INL under contract

DE-AC07-051D14517.
Highlights...

The average number of events at the INL each quarter has dropped this fiscal year from 20 in FY13 to 15 in FY14. The rate of significant events (those reported as Operational Emergencies, Recurring Issues, and/or

Significance Categories 1 or 2) is trending downward over the past 24 months

Over the past eight quarters, the average number of days between significant occurrences is increasing, indicating that significant events are occurring less frequently. An increase in the number of days between significant events is a positive trend.

This quarterly analysis reviews those events that were reportable through ORPS, events that did not meet ORPS reporting thresholds, some conditions tracked in LabWay, the causes of reportable events, and trending performed by the INL Operational

Performance Analysis Committee (IOPAC) group.

The report also provides a summary of the more significant Lessons Learned issued by INL.

\section{Occurrence Reporting Rates through the 4th Qtr FY14}

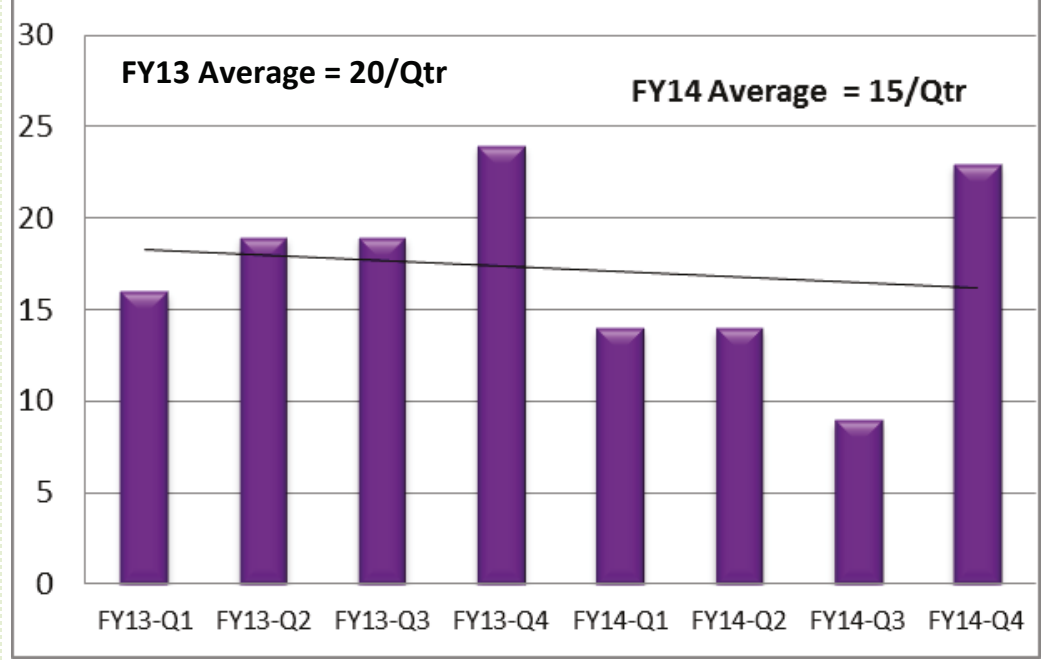

\section{Significant Occurrences Reported}

(Category OE, R, 1, and 2)

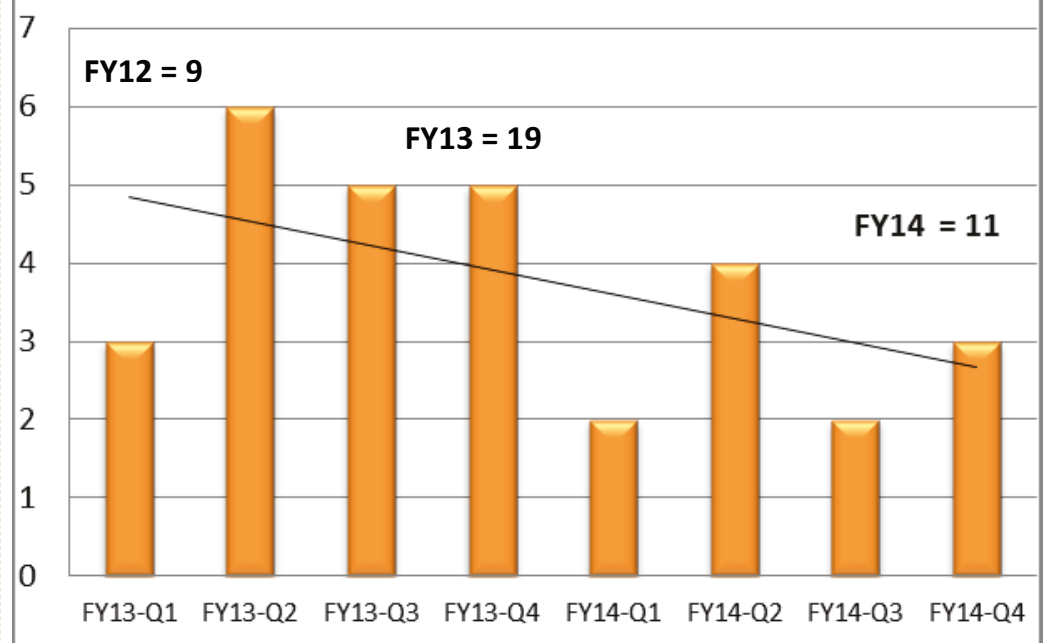

Average Days Between Significant Occurrences (Category OE, R, 1, and 2)

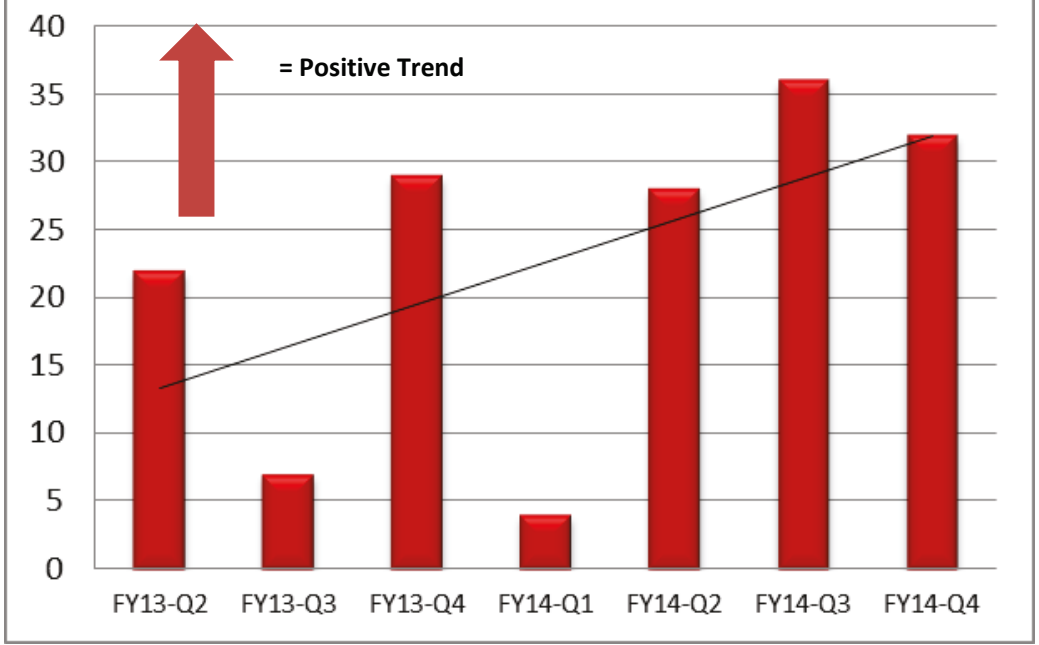




\section{INL Occurrence Trend Snapshots}

From 07/01/2014 through 09/30/2014, INL reported 23 new events to DOE, in accordance with DOE Order 231.1B. These events are analyzed to determine commonalities related to: Operational Emergencies (Group 1), Personnel Safety and Health (Group 2), Nuclear Safety Basis (Group 3), Facility Status (Group 4), Environmental (Group 5), Contamination and Radiation Control (Group 6), Nuclear Explosive Safety (Group 7), Packaging and Transportation (Group 8), Noncompliance Notifications (Group 9), and Management Concerns (Group 10).

In addition, INL reported 12 events through Initial Notification Reports and INL's local issues tracking software (LabWay) that did not meet ORPS reporting thresholds. There were no additional Significance Category A or B conditions reported in LabWay that were not already ORPS reportable.

\section{TREND SNAPSHOT}

Occurrences by Facility: When anlayzing a 12 month average (prior four quarters) of occurrences for each facility, the Advanced Test Reactor, the Analytical Labs, Materials and Fuels Complex, and Specific Manufacturing Capability reported a greater number of reportable events than their prior 12 month average. The number of Initial Notification Reports (INRs) submitted during the reporting period increased from 13 last quarter to 24 this quarter.

ATR reported $43 \%$ of the events during this reporting quarter and MFC reported $30 \%$. Analysis of the nature and causes of all the reportable events is covered in additional sections of this report.

\section{TREND SNAPSHOT}

\section{Occurrences by Reporting Criteria:}

During FY14, INL has experienced the majority of events related to: Group 4, Facility Status (41\%), Groups 3, Nuclear Safety Basis (23\%), and Groups 2 Personnel Safety and Health and 5, Environmental (both at $10 \%$ ). Comparative analysis to the balance of the DOE complex is shown in the chart to the right and is explained in each section of the report that follows.
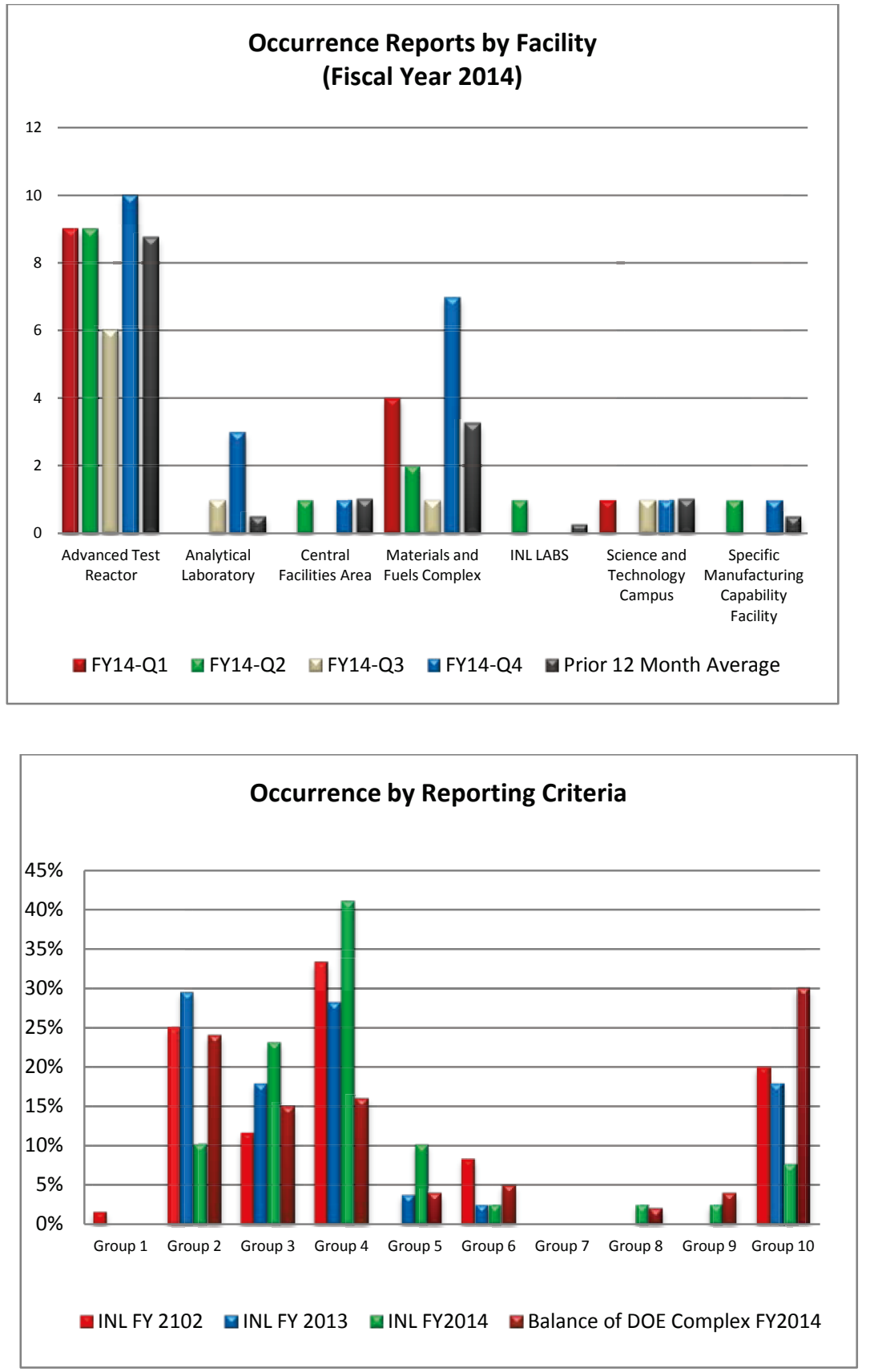


\section{TREND SNAPSHOT}

Lessons Learned Events: For the $4^{\text {th }}$ Qtr FY-14, the use of Lessons Learned is showing increased improvement. Key factors in maintaining likelihood of events are for personnel to exercise high standards, with respect to behaviors, that can lead to events, by relating behaviors to actual events. To address this concern, Quality and Performance Management benchmarked Lessons Learned programs in place throughout the complex and developed actions aimed to improve Lessons Learned use across the INL. One improvement includes development and implementation of a standardized one page Lessons Learned format. An additional improvement includes implementation of the OpexShare site to replace the existing Lessons Learned database in use by INL.

The Idaho National Laboratory (INL) Lessons Learned Program is an integral part of the feedback and improvement processes required by the Department of Energy (DOE). Operational excellence requires the use of internal and external operating experience information (OEI) to minimize the likelihood of undesirable behaviors and promote noteworthy practices. Lessons learned are systematically evaluated and implemented to continuously improve performance. During the $4^{\text {th }}$ Qtr FY-14, there were roughly 100 Lessons Learned internally generated and/or lessons shared from other sites by Materials and Fuels Complex (MFC), Energy and Environment Science and Technology (EES\&T), Advanced Test Reactor (ATR), and Facilities and Site Services (F\&SS).

Of those Lessons Learned, four INL lessons were entered into the INL database to be shared across the INL and, when appropriate, with other DOE facilities. An additional 31 lessons from other DOE facilities or organizations were also shared with INL personnel through the INL Lessons Learned database. The four lessons submitted by INL are summarized below:

\section{Vehicle Damage Due to Backing Maneuver}

Lesson 2014-1683 (Blue -Information)

A federally owned vehicle was traveling to INL Site, transporting a visitor for DOE benchmarking activities. The driver noticed that a Red Cross Van transporting blood drive equipment to the site was parked beside the highway with the hood up. The driver stopped to offer assistance but was several hundred feet past the van when his vehicle stopped. The shoulder of the road was narrow and there was some near-lane traffic, so the driver did not think it safe to exit the vehicle. Using the driver side and center rear-view mirrors as visual reference, the driver then backed the vehicle toward the van, to close the distance. The selection of visual reference was to address the primary concerns of passing traffic, closing distance to the van, and maintaining close proximity to the solid white line at the edge of the road which would ensure passenger-side tires would not approach the outside edge of the shoulder.

A 360-degree check was not performed properly before initiating the maneuver, so the driver did not notice the proximity of road-side reflectors and snow-height indicators at the edge of the shoulder. During the maneuver, the vehicle contacted one of these poles, scraping the passenger-side door and removing the passenger-side mirror and chrome lettering. There were no personnel injuries associated with the event, however, avoidable vehicle damage costs were approximately $\$ 2,315$.

It is important to perform a 360-degree situational awareness evaluation prior to initiating vehicle backing maneuvers. This helps identify hazards that may not be visible to the vehicle operator through windows or rear-view mirrors. Situational awareness prevents accidents, personal injury, and vehicle damage from potential unseen obstacles in the vehicle travel path.

\section{Accurate Weights for Waste Containers}

Lesson 2014-1684 (Blue - Information)

This lesson was originally identified in 2007 but not entered into the Lessons Learned Database. The original contact person requested that it be entered as it is still applicable. 
In November 2007, after shipment to the receiving facility, a PCB/Mixed Low Level waste container was found to weigh more than the weight reported in the waste tracking system. The inaccurate weight resulted from reliance solely upon aggregating the content weights-without verifying the final drum weight.

The waste container in question held several bagged and poly wrapped waste items. During packaging the bagged items were weighed using a calibrated scale; however, a few of the larger items exceeded the weight limits of the scale. Those items were weighed using a forklift dynamometer since the floor scale typically used for weighing heavier items was temporarily out-of-service. The final weight reported on the waste tracking system container profile was then determined by summing the weights of all the items in the container. The sum of the weights was then used as the final container weight reported on the shipping documents.

In this situation, the error did not affect the container source term or violate the weight restrictions for the shipment; however, the discrepancy illustrates the potential impacts an error in weights-constituent weights or final drum weightcould have. When weights are used to figure radionuclide activities, for example, an inaccurate source term could be calculated and reported.

In turn, this incorrect calculation could yield an incorrect NRC waste classification, which could then result in a violation of the receiving facility's waste acceptance criteria. Accurate weights are needed on waste containers to ensure compliance with regulations and receiving facility waste acceptance criteria. Incorrect waste container weights can result in incorrectly reported constituent concentrations and source terms, resulting in a non-compliance with regulations and receiving facility waste acceptance criteria.

\section{Inadvertent Premature Public Availability of Information}

Lesson 2014-1690 (Blue - Information)

On May 30, 2014, a draft website on the INL external portal platform was populated with information scheduled for public release the next day, a milestone for the project. Project personnel were informed by DOE of a new internal review earlier that week and that the website should not be activated until notified by DOE, but website development should continue while the issue was being resolved just in case there was a quick resolution.
No notification was received by May 31, 2014, so the site was not activated by linking it to the INL external homepage. On June 3, 2014, DOE discovered that the content of the website had been found by a Google web crawler and the information was available via Google search. Upon identification of the issue by DOE and notification of project personnel at INL, the website links were immediately disabled and associated pdf files removed and the related activities were reviewed. At this time, it is unclear what, if any, impact the inadvertent temporary availability of the information had.

The root cause of the event was an automated bottom-up update of the INL site index. Software designed to automatically perform a daily update of the index located the subject content, identified it as unrestricted, and added the associated url addresses to the index. The INL external homepage includes a link to the index, which allowed the top-down Google web crawler to find the url addresses.

The lesson we can learn from this event is that automated systems, designed to make information available to the public, may inadvertently result in premature release of information if not properly controlled.

\section{Lockout/Tagout: The Fatal Five}

Lesson 2014-1696 (Blue - Information)

INL issued a lessons learned on the inherent dangers of working on energized equipment. Fifty thousand workers are injured and 120 workers are killed annually in equipment startup accidents. The five most common reasons employees are hurt during lockout and tagouts are:

- Failure to stop equipment;

- Failure to disconnect the power source;

- Failure to drain residual energy;

- Failure to confirm co-workers are not in the path of danger before re-starting equipment; and

- Failure to clear work areas of tools before restarting equipment.

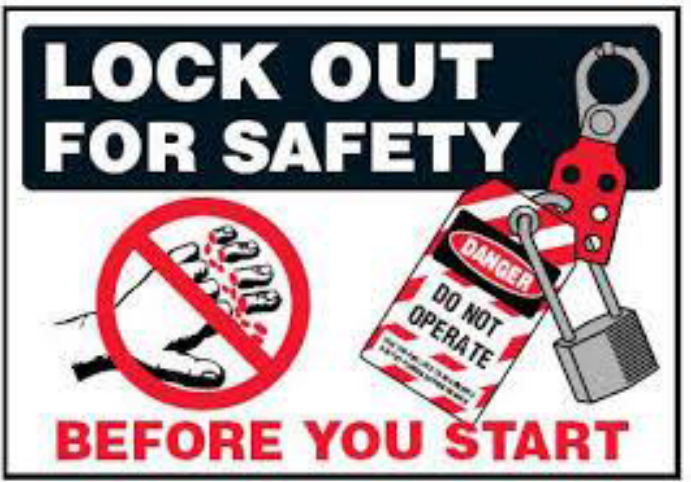




\section{Other Significant Lessons Shared}

Lesson 2014-1706 (Yellow- Caution)

Small problems left uncorrected over time can add up to enable a significant operational event. Deficiencies need to be fixed promptly and tracked to completion.

This lessons learned was offered as a brief summary from the DOE Accident Investigation Report “Underground Salt Haul Truck Fire at the Waste Isolation Pilot Plant (WIPP) near Carlsbad, New Mexico. On Wednesday, February 5, 2014, an underground mine fire involving a salt haul truck occurred at the WIPP. There were 86 workers in the mine (underground) when the fire occurred. All workers were safely evacuated. Six workers were transported to the Carlsbad Medical Center (CMC) for treatment for smoke inhalation and an additional seven workers were treated on-site. DOE commenced an investigation due to losses costing greater than $\$ 2.5$ million.

An Accident Investigation Board identified the direct cause of this event to be contact between flammable fluids (either hydraulic fluid or diesel fuel) and hot surfaces (most likely the catalytic converter) on the salt haul truck. The root cause of this accident was due to the failure of Nuclear Waste Partnership LLC and the previous management and operations contractor to adequately recognize and mitigate the hazard regarding a fire in the underground. This includes recognition and removal of the buildup of combustibles through inspections and periodic preventative maintenance, and the decision to deactivate the automatic onboard fire suppression system.
Lesson 2014-1694 (Yellow- Caution)

Inexperience and ineffective communication among workers/ supervision can lead to serious injuries while moving heavy items. Missed opportunities to effectively use work processes, lack of communication of previous issues, and inadequate recognition of risks can lead to legacy hazards being passed down to your fellow employees. In this event, a worker was severely injured during a material handling task.

On March 31, 2014, an Oak Ridge National Laboratory (ORNL) employee was severely injured when a $1,585 \mathrm{lb}$. scattering chamber on a stand with wheels overturned while it was being moved down a ramp into the bed of a box truck. The scattering chamber assembly was 65 inches tall and had a high center of gravity. The work activity was to load the scattering chamber and stand into a privately-owned truck after it was sold as excess equipment at auction. Two Salvage Handlers were moving the scattering chamber - one Salvage Handler was behind the chamber as they guided it down the slightly inclined (6.25\%) loading ramp and the other Salvage Handler was in the fall zone in the direction of motion. When the leading wheels reached the transition between the loading ramp and the truck bed, the scattering chamber tipped over and onto the Salvage Handler in the path of travel, pinning him underneath. Staff from within the facility responded immediately, removed the scattering chamber from the injured employee, and rendered aid. The employee sustained fractures to his lower legs, a broken right thumb, and several lacerations. A full investigation of the accident and activities leading up to it was conducted. This accident was determined to be preventable by the investigation team. 

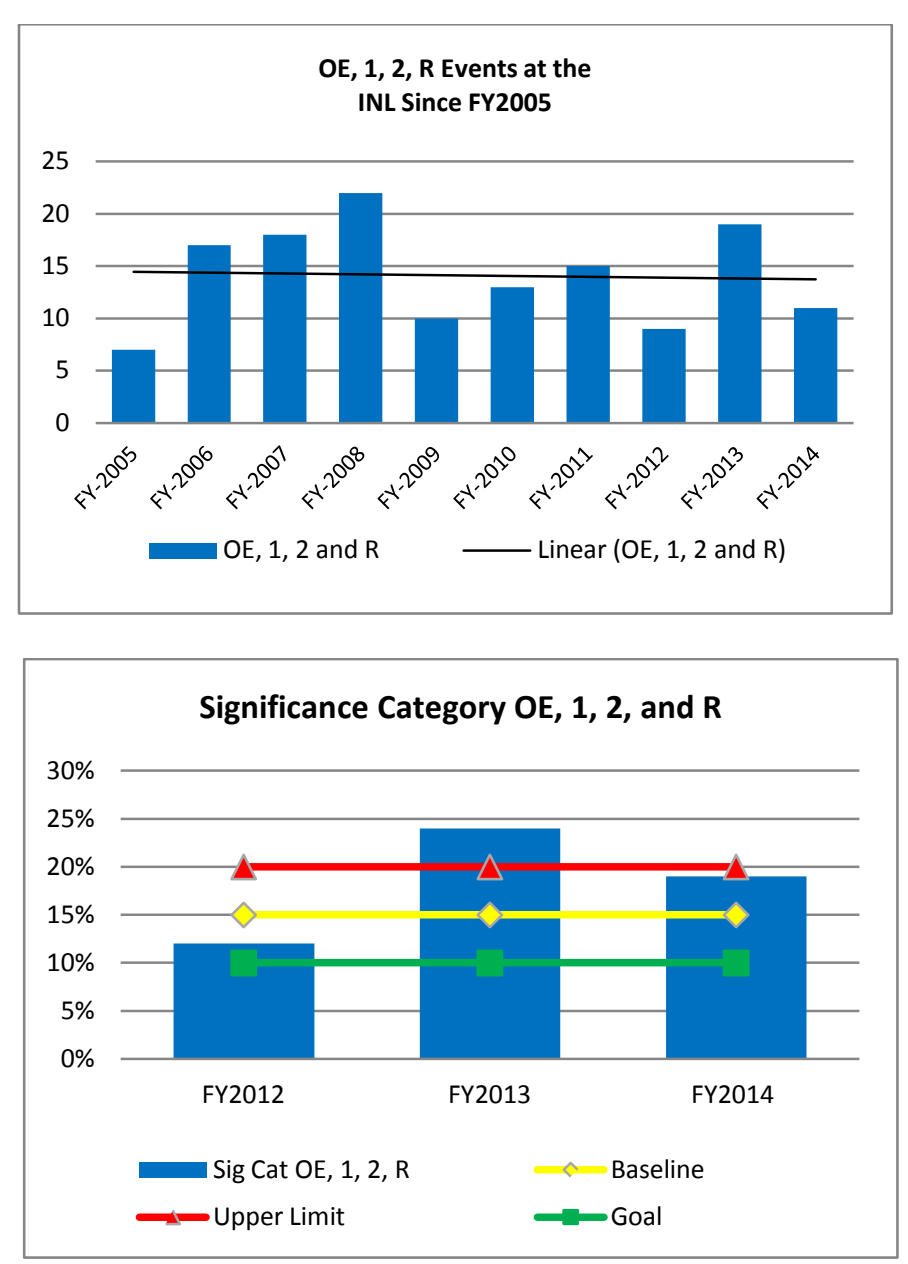

INL has established a new set of performance metrics to monitor events. The measures compare INL event reporting to reporting at other facilities in the DOE complex.

As shown in the first chart to the left, INL is realizing a slight downward trend in the number of significant events (Sig Cat $\mathrm{OE}, 1,2$, and $\mathrm{R}$ ) occurring at the INL since BEA took the contract over in FY2005.

However, INL continues to experience a greater percentage of reportable events in these four categories than other DOE facilities (see next chart). In addition, The INL is experiencing a slightly lower percentage of Significance Category 3 events than those experienced throughout the rest of the complex, but continues to have a similar percent distribution of Significance Category 4 events.

Additional analysis on how INL measures up to the balance of the complex in each of the reporting criteria groups is provided throughout this report.

\section{$4^{\text {th }}$ Qtr FY-14 GROUP 1 - OPERATIONAL EMERGENCIES}

There were no operational emergencies reported during the $4^{\text {th }}$ quarter of FY-14. The last operational emergency was reported in April 2012, when boron triflouride gas leaked from a neutron detector (NE-ID-BEA-INLLABS-2012-0003). The rate of occurrences of operational emergencies continues to trend at zero.

When compared to the balance of the DOE complex, the rate of occurrence of these types of events at INL is consistent with those reported elsewhere. In FY-14, only two Operational Emergencies were reported throughout the DOE Complex. The INL is consistent with the rest of the DOE Complex in that zero percent of our events were reported in the Group 1 reporting group. Throughout the balance of the complex in FY14, two operational emergencies were reported in FY14.

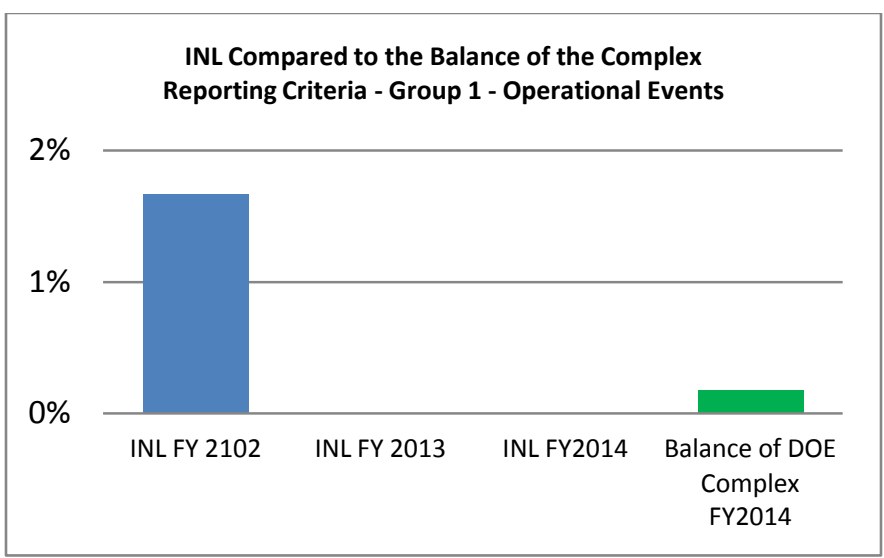


were also documented in the INL issues management software or reported via INRs during the current quarter.

\section{TREND SNAPSHOT}

Personnel Safety and Health Events: For $4^{\text {th }} \mathrm{Qtr}$ FY-14, seven events occurred that were related to personnel safety and health and were communciated to DOE through ORPS. Six additional events were reported via INRs or directly into LabWay that did not meet the ORPS thresholds but were related to personnel injuries. The rate of occurrence of reportable personnel safety and health events continues to trend downward when trended over eight reporting quarters. However, the number of events that occurred during the $4^{\text {th }}$ Qtr of FY14 shows a noted increase. An analysis of the events over the last 12 months did not reveal any commonalities that would indicate a recurring event exists.

When compared to the balance of the DOE complex, the rate of occurrence of Group 2 events at INL was consistent with those reported elsewhere in the complex during FY12 and FY13, but dropped considerably below average in FY14. In FY14, ten percent of INL's reportable events were reported under Personnel Safety and Health criteria.

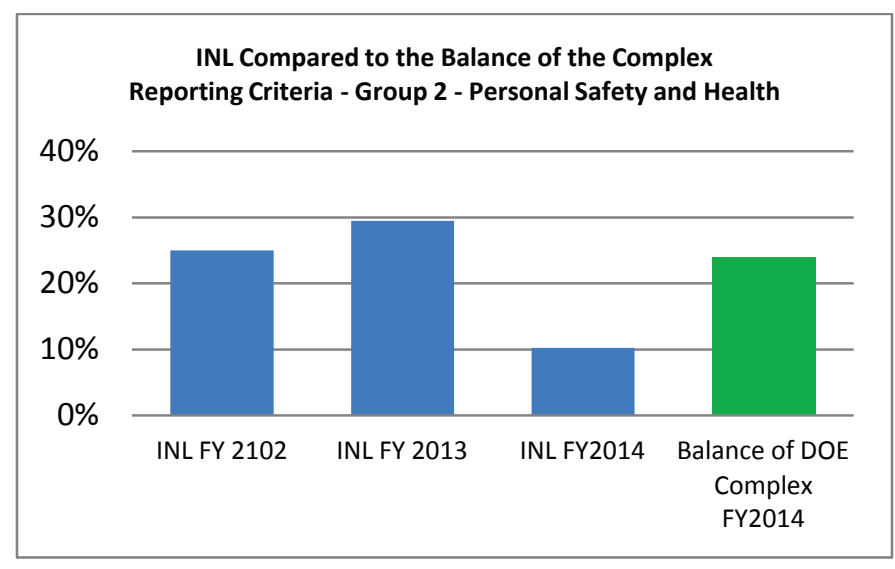

Personnel safety and health occurrences were the second most frequently reported event type, accounting for 16 reportable events in the last 12 months. Seven events categorized under the personnel safety and health reporting criteria were reported during the $4^{\text {th }}$ Qtr FY-14. These are summarized below. Additionally, six non-reportable events

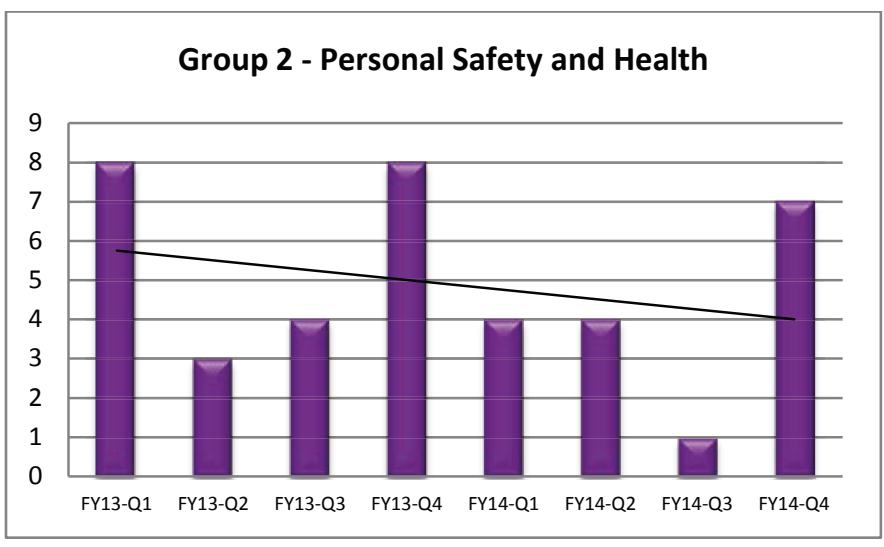

Failure to establish Lock Out/Tag Out (LO/TO) Prior to Plasma Hearth Project (PHP) Construction Demolition NE-ID--BEA-MFC-2014-0003 (Significance Category 3) On Monday, July 14, a lockout/tag out (LO/TO) was completed on the Plasma Hearth Project (PHP) equipment located within the Transient Reactor Test (TREAT) facility to allow a construction subcontractor to commence Decommissioning and Demolition (D\&D) on designated systems/components. The following day, the TREAT shift manager was walking down the job site and noticed that the criticality light on the side of the PHP structure had been disconnected and removed. The light was not covered under the current LO/TO. While the criticality light was not currently energized, the potential for it to become energized existed. It was determined that the LO/TO was correct for the covered systems/components and the contractor had signed onto the LO/TO. The contractor performed flagging of systems that were tagged out and ready for D\&D and the criticality system was not flagged per construction.

Upon learning of the event, all contract work was stopped and a formal stop work was issued. The system was deenergized and a LO/TO was installed. Causal to the event was the fact that the electrician's original outage request had included the criticality light but in the approved outage, the light was not listed. Instead of thoroughly reviewing the lockout tagout record, the electricians assumed the light was on the request and when the light was checked for energy and none was found, it further supported their assumptions.

This event stresses the importance of reviewing all work control documents as things may change from the original plans. 
Removal of Flowmeter while Under LO/TO Protection without being Signed on LO/TO

NE-ID--BEA-AL-2014-0002 (Significance Category 4)

The instrument gas lines for the Fresh Fuels Glovebox (FFG) in the Analytical Laboratory $(A L)$ were locked out to support reconfiguration during the initial setup and testing of newly installed instruments. Part of that work involved a flowmeter that was borrowed from Fuels and Applied Science Building (FASB) in mid-June and temporarily installed in the FFG while the new one was awaiting arrival.

On July 16, 2014, a researcher noticed that the flowmeter was missing from the FASB system, discussed this with the Principal Investigator (PI), and it was determined that the borrowed flowmeter could be returned to FASB because the $\mathrm{PI}$ had received information that the new flowmeter had been installed in the FFG in the AL. The researcher notified the AL Shift Supervisor that he was going into the lab to retrieve a piece of borrowed equipment and return it to FASB. Once inside the lab, the researcher identified that the new flowmeter was attached to the outside of the glovebox, but that the borrowed flowmeter was still installed in the gas system. The researcher then removed the borrowed flowmeter and reconnected the gas lines to the system. The borrowed flowmeter was taken back to FASB and reinstalled in that system for use.

Following discovery, the system was verified to be in a safe configuration and actions were initiated to address shortcomings in work on compressed gas systems. Proper communications between the two workgroups and an understanding of the hazards associated with work on compressed gas systems would have prevented this event.

\section{Failure to Utilize Lockout/Tagout on Argon Instrument Line}

NE-ID--BEA-FASB-2014-0001 (Significance Category 3)

In June 2014, a researcher had removed a flowmeter from an argon gas system supplying an analytical instrument in the FASB without establishing a LO/TO. The system was supplied by gas cylinders through a regulator (maximum value of 60 psi but typically maintained at approximately 7 psi). On July 16, 2014, the flowmeter was reinstalled without establishing a LO/TO.

The flowmeter was removed from FASB so that it could be installed in the FFG in the AL for initial setup and testing. A Principal Researcher (PR) checked in with the shift supervisor at FASB to perform work on a dilatometer but did not specify that they would be breaking into a pressurized system and removing parts. The gas bottle and valves on the upstream and downstream side of the flowmeter were secured and the flowmeter was removed from the dilatometer and taken to the AL. The PR then opened the gas bottle and valves supplying argon to other instruments.

On July 16, 2014, a researcher wanted to use the dilatometer at FASB and noticed that the flowmeter was missing from the system. This was discussed with the PR and it was determined that the flowmeter could be returned to FASB because the PR had received information that the new flowmeter had been installed in the FFG in the AL. The researcher obtained the flowmeter from the $A L$ and reinstalled it on the dilatometer at FASB and began to use the system.

This condition was discovered on July 21,2014 , as a result of a fact finding meeting that occurred at the AL when it was discovered that the PR removed the flowmeter from the FFG and did not sign onto the LO/TO that was in place (see NE-ID-BEA-AL-2014-0002).

Following discovery, a walk down and evaluation of the system was performed by management and subject matter experts. The system was determined to be in a safe configuration.

Causal to the event was that personnel incorrectly identified the hazard to be argon at approximately 7 psig and determined that this did not need to be identified or mitigated in the procedure covering this activity. This was incorrect because the flowmeter was downstream of a regulator that was adjustable up to 60 psig. Additionally, communications between the researcher and supervisors at both facilities regarding scope of work, system status, hazard mitigations, and unexpected conditions found in the field were less-than-adequate. Finally, training and laboratory guidance for LO/TO of pressurized system using gas bottles is not clear, which has resulted in inconsistent interpretations and application of the requirements.

\section{Lockout/Tagout Hung without Tags}

NE-ID--BEA-AL-2014-0003 (Significance Category 4)

A LO/TO was developed for a repetitive research activity and has been used on a fairly frequent basis for over a year. The LO/TO was hung on July 15, 2014, in preparation for future work. On August 5, 2014, two researchers were escorted on to the LO/TO and performed work. When they completed their work, they notified the Shift Supervisor that the LO/TO could be removed. During the removal process, it was discovered that the locks were hanging as expected but personnel failed to hang the tags. Following discovery of the event, work was stopped, the system was verified to be in a 
safe configuration, and removal of the LO/TO was suspended pending further evaluation.

An apparent cause analysis found that the tags were missed by both the installer and the work group representative due to mental lapse associated with a repetitive task, short staffing, and perceived time pressure to complete the task. Self-checking and peer-checking tools are crucial to ensure the work is performed correctly. If shortcuts are taken, work steps can be missed.

\section{Inadequate Lockout/Tagout on Water jet Cutting Machine in TRA-662 \\ NE-ID--BEA-ATR-2014-0021 (Significance Category 4)}

On July 24, 2014, a minor maintenance activity was being worked to clean out a water jet sump located in building TRA662. A majority of the grit was cleaned out using a backhoe, but it was determined that the remaining material needed to be manually removed using shovels. The laborer foreman consulted the Utility Area Supervisor (UAS) concerning the need for a LO/TO. The UAS decided to hang a simple LO/TO and directed that the appropriate zero energies be performed. The UAS failed to use Form 434.37, "Documentation of Lockout/Tagout Training for Escorted Personnel" and directed the laborers performing the work to hang personal LO/TO locks and tags in accordance with section 4.3 of LWP-9400, "Lockouts and Tagouts."

Attention to detail is crucial to ensure that procedures are understood and followed.

\section{Employee Injures Arm in North Holmes Laboratory (IF- 639)}

NE-ID--BEA-STC-2014-0002 (Significance Category 3)

An employee was using an industrial cart to transport a piece of equipment when the cart abruptly moved laterally due to a cracked and uneven concrete floor surface. The employee righted the cart with his left hand; the action resulted in a muscle twinge. The load remained in the cart. The employee immediately reported the event and reported to medical. Medical referred him to his physician who prescribed pain medication and specialist referral. The employee was released back to work with restrictions. Evaluation by a private physician determined the employee required surgical repair of his bicep. An analysis of the event found that corrective maintenance of the floor was less-than-adequate and causal to the event. The North Holmes Laboratory is located in an old grocery store. The floor in this building has cracks, pits, and uneven surfaces. BEA personnel had notified the building owner of the poor condition of the floor; however, nothing had been done to correct this condition.
The poor floor condition contributed to the cart becoming unstable.

An important lesson we can take away from this event is to follow through with requests for deficient area repair, ensure the repairs are addressed in a timely manner, and while waiting for repairs, take extra precautions and time.

\section{Potential Exposure to Energized Broken Street Light Cable at ATR Complex}

NE-ID--BEA-ATR-2014-0026 (Significance Category 3)

On September 18, 2014, the ATR Management Team questioned if a broken street light cable near building TRA609 was an exposed energized conductor. The broken cable end was stuck in a crack of the wooden light pole and was 12 feet above the ground. Per the National Fire Protection Association 70E, the Limited Approach Boundary for this cable is ten (10) feet. Personnel walking near the base of the light pole would be entering the Limited Approach Boundary. Following repair to the cable the ATR Electrical Foreman informed ATR Operations that the cable was energized prior to having power removed for the repair. Based on scuff markings on the wooden pole the cable had been broken for some period of time. Personnel contact with the broken cable was not possible without the use of a ladder or personnel lift.

The cause of the event was found to be a defective part with a contributing cause of exposure to the elements. Personnel should be aware and watch for equipment degradation, especially when equipment is routinely exposed to extreme weather conditions.

\section{SMC-CO-2014-1065}

On July 8, 2014, an Operator at Specific Manufacturing Complex (SMC) was injured when his thumb went between the rollers of a roller leveler while configuring sheet metal. His foreman accompanied him to the SMC dispensary, where he was evaluated and his wound bandaged, and then sent to Central Facilities Area (CFA) Medical. At approximately 1030, CFA Medical sent him to Mountain View Hospital in Idaho Falls for surgery on his thumb.

A momentary lapse in focus can result in injury. Attention to detail must be stressed in all aspects of work, especially work that involves moving parts.

\section{CO-2014-3794}

On July 24,2014 , an INL security officer was participating in a $40 \mathrm{~mm}$ qualification course which required the officer to shoot from both the standing and kneeling positions. During the course, the officer was recovering to the standing 
position from kneeling. While in this position, the officer stated that he experienced slight discomfort across and under his left knee cap. The officer was wearing kneepads while shooting and was able to complete his qualification course; however, later that day the officer reported that his knee appeared to be slightly swollen. At this time, proper notifications were made. The officer was asked and declined to have INL medical personnel look at the knee. The officer was instructed to inform the Rangemaster if the knee discomfort worsened.

The following day, the officer noticed that his knee was becoming swollen and it began aching. The officer reported to Medical on Monday, July 28, to have his knee looked at and it was determined that the officer either had a slight tear in his meniscus or that he may be suffering from gout.

The officer was released to return to work with restrictions. The officer reports that he has not had any previous issues with his left knee and did not know of any event that could have injured his knee with the exception of kneeling during the qualification course.

Although we often take the proper precautions to protect ourselves during work evolutions, in this case, wearing proper knee protection, injury sometimes does occur. Follow-up with medical professionals should be prompt to ensure the situation is not severe and that treatment can begin sooner than later.

\section{CO-2014-3796}

During a maintenance evolution, an INL vehicle repair specialist was explaining the operation of the INL Fire Dept. breathing air tank recharge trailer to another repair specialist. During the discussion, the repair specialist was explaining a feature of the compressor which allows it to turn freely when de-energized and de-pressurized (free-wheel). The specialist then moved the compressor drive belt (using same technique used to inspect v-belts) to demonstrate this feature when his right thumb was pinched between the belt and pulley, resulting in a fracture at the tip of his right thumb.

The vehicle repair specialist immediately reported the injury to his supervisor and he was escorted to CFA medical. After initial evaluation and treatment, the mechanic was escorted to Idaho Falls for further treatment, where it was determined that the tip of the right thumb bone was broken. The employee was allowed to return to work on limited duty and will have additional medical treatment to pin and set the bone.
On July 31, 2014, a safety pause was conducted during the Big Shop pre-shift meetings, with emphasis on "Don't be a Target" (Where are my fingers/hands/head? What could potentially trap or pinch me?).

A Human Performance Improvement (HPI) Mini-Review (FRM 212.01) was conducted on July 31, and found the following. The vehicle repair specialist had over 20 years experience working on fire and other emergency equipment. The specialist was asked about the operation of the trailer and used the opportunity as a teaching moment for the other specialist. The specialists were not under time or schedule pressure and no other events were taking place to impede or distract the employees.

We can learn that ad-hoc learning opportunities are not necessarily free from hazards. Personnel must pay close attention to detail, even when they are not perfomring work but are in a teaching mode.

\section{CO-2014-3957}

An INL employee was removing a drum from the inside wheels on a low boy trailer, using an approved dolly. When employee lowered the dolly to clear the frame of the trailer, the dolly flipped out of level, pinching the employee's hand. The hand was caught between dolly and the trailer frame, causing a blister and contusion to the webbing between the employee's thumb and forefinger. There are inherent hazards associated with using drum dollies. Heavy, bulky loads and shifting weights make moving drums difficult at times. Because of this, employees must always be focused on the actions they are taking and must ensure their body parts are out of the line of injury.

\section{CO-2014-3977}

On August 18, 2014, an individual fractured his left ring finger when he attempted to prevent a door from shutting. The employee's finger was smashed between the door and the door jam. Self-closing doors normally slow down during automatic closing, then release to close swiftly just prior to contacting the door jam. The door to Room 110, labeled "Reactor Supervision" in MFC-720, does not slow down prior to closing. This door is infrequently used and located in an area which is not frequently accessed.

The door was evaluated by industrial safety and determined not to cause increased potential for injury. The door was also evaluated by INL carpenters who made some minor adjustments to the door. All other doors with similar door closures in the complex were inspected and adjusted if adjustments were needed. 
We can learn that event the simplest, mundane tasks can cause injury. However, by learning from and responding properly to events such as this, we can prevent future injury to others.

\section{CO-2014-4162}

On September 8, 2014, an operator at the Fuel Conditioning Facility (FCF) experienced a minor electrical shock due to a faulty ground wire in an emergency stop box. The operator notified his immediate supervisor and was immediately escorted to medical where he was evaluated and released to work without restrictions.

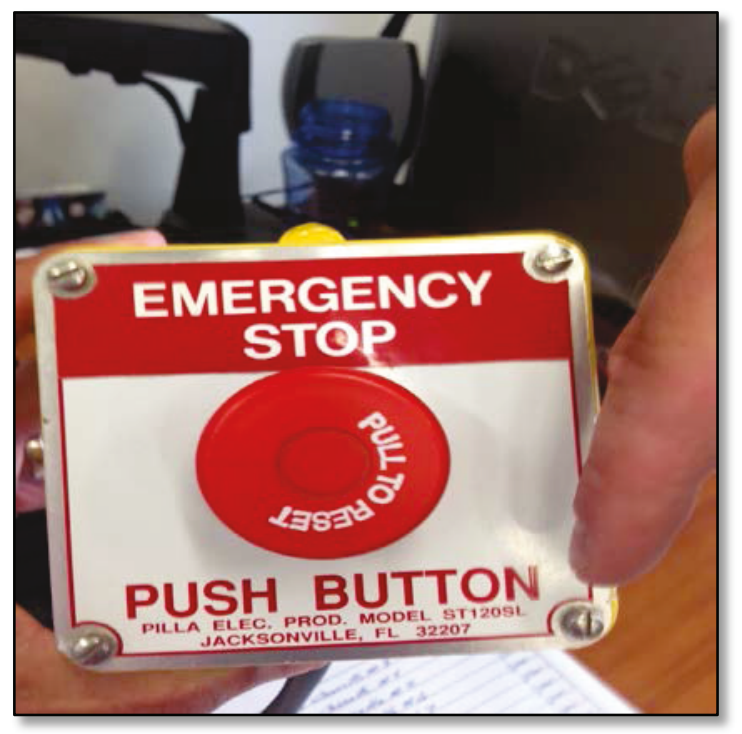

The area was barricaded and all E-stops were removed from the operating floor. Upon inspection, electricians discovered a broken ground wire inside the E-stop box; $113 \mathrm{~V}$ potential was present.

An investigation into this event found that the wrong wire type for this application was used and the wire was not code compliant. Additionally, a lack of stretch relief was present on the wire and all stress was on ground wire. A practice of hanging the e-stop boxes by the cable also likely contributed to the broken wire. In general, the poor design of the e-stops (from early 1990's) was revealed. The E-stops were made compliant and were placed back in service.

\section{CO-2014-4038}

On August 21, 2014, an observation was made of a manbasket on a fork lift. The basket was being used to move furniture and was accessed by personnel in raised position to unload furniture. The man-basket was evaluated once the fork lift lowered back to ground level. It was discovered that no means of attaching the man-basket to the fork lift were provided. The operator at ground level indicated the manbasket had pockets where the forks engaged, which held it in place, and that no other means of securing the man-basket were necessary. Several requirements that must be met when allowing personnel to work from a man basket elevated by a forklift were not met including: the platform attachment means are applied and the platform is securely attached to the lifting carriage; the lifting carriage and/or forks are secured to prevent them from pivoting upward; before elevating the platform, the area must be marked with cones or other devices to warn of work by elevated personnel; the combined weight of the platform, load, and personnel shall be displayed in the form of a label on the man-basket and shall not exceed one-half (1/2) of the fork lift truck capacity indicated on the lift truck nameplate. (Reference ASME B56.1 sections 4.17 .3 (a) through (0)).

The forklift operator was told that the man-basket needed to be secured. Supervision was notified and a DANGER, Defective Equipment Tag, was placed on the equipment. Equipment Operators and Heavy Equipment Operators will be briefed on the requirements of using a man-basket with a forklift.

\section{CO-2014-3789}

A subcontractor was moving UPS batteries from the shipping pallet onto a cell handler (transport cart) for loading onto the UPS battery rack at ATR-670. There are over 200 batteries to be placed in the rack, each weighing $677 \mathrm{lb}$. The batteries, transport cart, and racks are government furnished equipment (GFE) provided to the subcontractor. While manually sliding the battery from the pallet to the cart, a gap occurred when the battery engaged the cart. The cart has a brake mechanism that is not effective if variances in the floor are present. The battery slowly tipped towards the cart, due to the gap, and came to rest on the cart, damaging a battery vent tube that spilled approximately two cups of acid onto the concrete floor. No injuries occurred due to the event. Battery was up righted, notifications were made, spill was contained and properly disposed, and the area was preserved and examined for noxious fumes. A formal stop work was issued by Project and Construction Services for the battery portion of the subcontract and corrective actions requested.

The brake for the transport cart should have been pressured against the ground to prevent movement while the battery was being loaded. However, the brake was not long enough to contact the ground securely, allowing backward movement and causing the battery to tip over toward the cart as it moved backwards. 


\section{TREND SNAPSHOT}

Nuclear Safety Basis Events: Two nuclear safety basis events were reported in the $4^{\text {th }}$ Qtr FY-14. The number of nuclear safety basis events increased from the one reported last quarter and the rate of occurrence of nuclear safety basis is trending slightly downward over the past two years. All nine of the events that occurred this fiscal year were repored at the ATR complex; eight of the nine were related to potentially inadequate safety analyses at the ATR facility and the ATR Critical facility. An analysis of the ATR Potentially Inadequate Safety Analysis (PISA) events did not reveal any commonalities. The PISAs are the result of increased rigor in evaluating existing safety analysis at ATR and identifying legacy problems with the analyses.

When compared to the balance of the DOE complex, INL reports a higher percentage of reportable issues in the Group 3 - Nuclear Safety Basis than the rest of the complex. The Nuclear Safety Basis events reported at INL is not unexpected and is attributed to increased rigor in assessing safety of the ATR. This rigor is in response to lessons learned from the Fukushima accident in Japan and attributed to hiring a new group of safety engineers with a fresh set of eyes. In FY-14, $23 \%$ of INL's reportable events were reported under Nuclear Safety Basis criteria compared to $15 \%$ across the DOE complex.

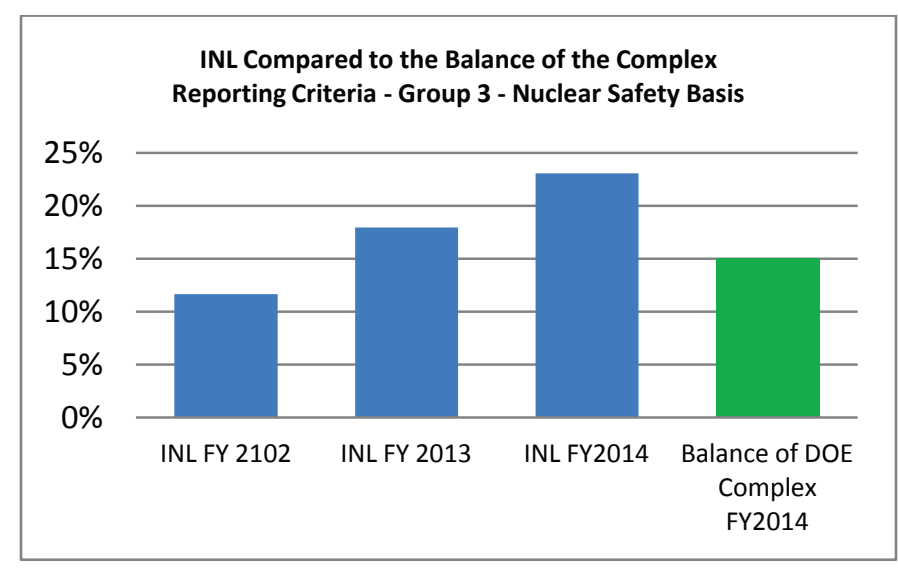

Although the distribution of nuclear safety events at INL has increased during the last three fiscal years, the number of reportable Nuclear safety basis is trending downward. Nuclear Safety Basis events are the third most frequently reported event type at INL, accounting for nine reportable events in the past 12 months. Three of the events were reported during the $4^{\text {th }}$ Qtr FY-14 and are summarized below.

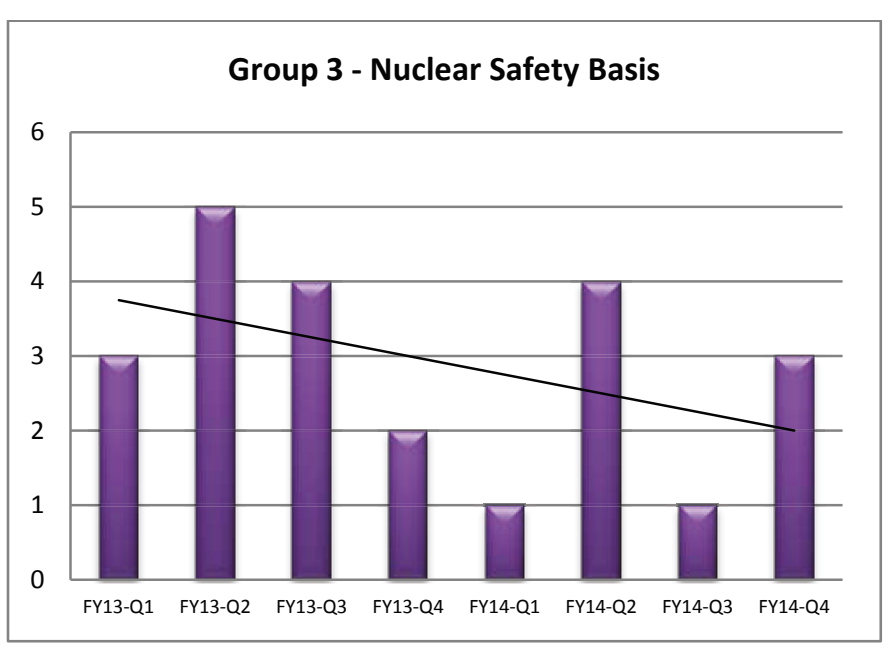

\section{Inadequate Change Control of New Calculation Method at the ATR Results in Noncompliance to Technical Safety Requirements (TSR)}

NE-ID--BEA-ATR-2014-0019 (Significance Category 2) On March 7, 2014, during preparations for ATR operating Cycle 156A, a Potentially Inadequate Safety Analysis (PISA) (ATR Complex-USQ-2014-114) was initiated and an interim control applied to assure that an appropriate conservative approach is followed to define In-Pile Tube (IPT) inlet pressure. During preparations for Cycle 157A-1, it was determined that the limits for maintaining less than maximum IPT inlet and outlet temperatures was not carried forward to Experiment Safety Analyses Packages (ESAP) and Core Safety Assurance Packages (CSAP) for Cycles 155B and 156A. Preliminary calculations indicate that IPT protection criteria were not exceeded while this discrepancy existed during $155 \mathrm{~B}$ and $156 \mathrm{~A}$ cycle operations and had no impact on nuclear safety. At the time of discovery, the ATR was shut down for the Cycle 157A-1 outage. 
A cause analysis was performed and found that personnel performed steps incorrectly due to mental lapse; procedures were incomplete to drive correct actions; and the wrong revision of a document was used while performing verification of the experiment. Also, analysis of this event determined that implementation of the Integrated Safety Management System (ISMS) failed during the use of Core Functions 4, "Perform Work Within Controls," and 5, "Provide Feedback and Continuous Improvement."

This event underscores the importance of using Conduct of Operations and Human Performance tools, such as selfchecking and peer-checking, to achieve successful generation and issuance of critical documents. An expert-based organization, with expert-based procedures, limits the tools in place to reduce errors caused by time pressure, high work load, etc. Employees who lack the fundamentals of human performance behaviors can fall victim to error-likely situations.

\section{Declaration of Positive Unreviewed Safety Question (USQ) Concerning Unanalyzed Drop of an Experiment onto an ATR Fuel Storage Grid}

NE-ID--BEA-ATR-2014-0022 (Significance Category 2)

On August 18, 2014, a PISA (ATR Complex-USQ-2014-395)

was declared regarding an unanalyzed drop of an experiment onto an ATR fuel storage grid. The ATR Updated Final Safety Analysis Report (SAR-153) allows for storage of miscellaneous fissile specimens (experiments) containing < or equal to $365 \mathrm{~g}$ U-235 within the ATR canal storage grids, but does not restrict the movement of the experiments over fissile material within the grids.

A drop of the experiment onto the fuel storage grid may be postulated to occur. However, the consequence of a drop and subsequent spill of an experiment onto a fuel storage grid that contains ATR fuel elements has not been evaluated within the criticality safety analyses for storage in the canal fuel storage grids; therefore, the new information represents an unanalyzed condition that may not be bounded by the existing safety analysis. At the time of discovery, ATR was in POWER OPERATION with no experiment or fuel handling occurring. Therefore, no immediate action was necessary to place the facility in a safe condition. Analysis into this event is ongoing.

\section{Experiment Safety Analysis Errors Associated with Fueled Experiments Stored in the ATR Canal} NE-ID--BEA-ATR-2014-0023 (Significance Category 2) On August 26, 2014, an Engineering Advisory Board (EAB) meeting was held to discuss potential errors noted while developing a new generic experiment capsule Experiment Safety Analysis Package (ESAP). The error being discussed by the $E A B$ involved the bounding accident selection used to establish gram limit controls for fueled experiments stored in the ATR canal.

One experiment program ESAP, Advanced Fuel Cycle Initiative (AFCI), and likely others, have specified an incorrect fuel gram limit when compared to the bounding accident analysis assumptions. AFCl program capsules are currently stored in the ATR canal. ATR Technical Safety Requirements (TSR)-186, Limiting Condition for Operation (LCO) 3.9.1, Experiment Safety Margin requires an ESAP, shall demonstrate compliance to the ATR Plant Protective Criteria for Condition $1,2,3$, and 4 faults for Experiments or irradiation test material in the canal. An apparent cause analysis of this event is ongoing.

\section{Other Non Reportable Events}

There were no additional non-reportable events related to nuclear safety basis problems reported during the $4^{\text {th }} \mathrm{Qtr}$ FY-14. 


\section{TREND SNAPSHOT}

Facility Status Events: Facility status events accounted for $31 \%$ of the events reported in the $4^{\text {th }} \mathrm{Qtr} F \mathrm{~F}-14$. The rate of occurrence of facility status events is trending upwards over the past two years - a reversal from the downward trend reported last quarter. Over the past 12 months, ATR has reported 13 events that fall into the Facility Status Events categories; six of which were the result of a performance degradation of a safety class or safety significant component (SSC) when that component was required to be operable and four when the SSC was not required to be operable.

A review of the 13 SSC issues at ATR did not reveal a negative trend. The ATR SSC issues involved different equipment and different process systems.

When compared to the balance of the DOE complex, the percentage of occurrence of Group 4 events at INL is higher than that of the balance of the DOE Complex and has increased since FY-13. Almost half of the Group 4 events in FY-14 were related to performance degradation of a Safety Class or Safety Significance Structure System or Component. Forty-one percent of events reported by INL in FY-14 were reported under Group 4 criteria. In comparison, $16 \%$ of the events across the balance of the complex were reported under this group.

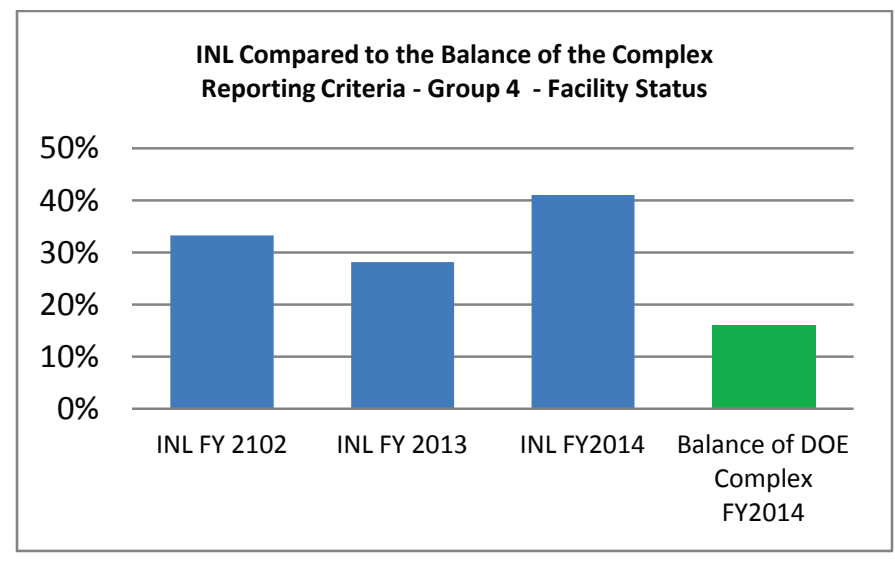

Events related to facility status have been the most frequently reported event type, accounting for 19 reportable events ( 13 events at ATR, 5 at MFC, and 1 at SMC), in the past 12 months. Seven facility status events were reported during the $4^{\text {th }}$ Qtr FY-14 and are summarized below.

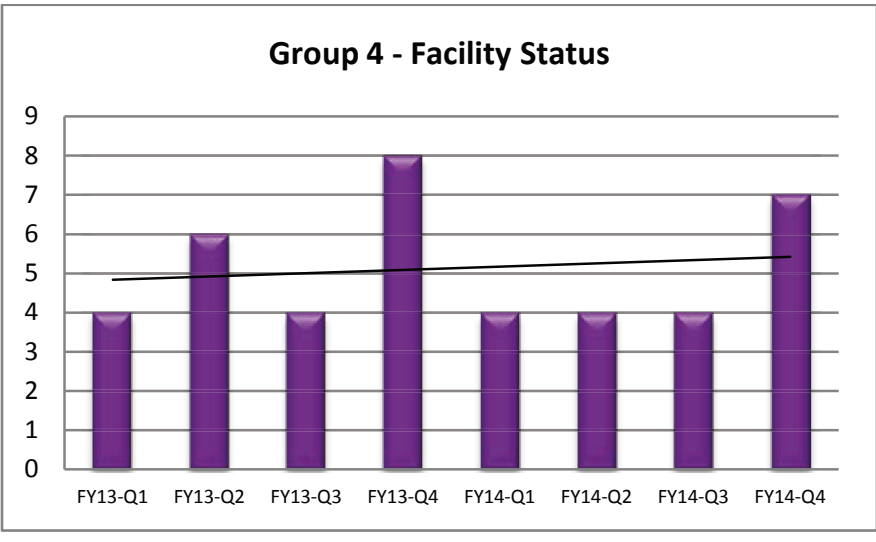

\section{Improper Control Wiring Termination for ATR M-7 Primary Coolant Pump}

NE-ID--BEA-ATR-2014-0018 (Significance Category 4)

On July 2, 2014, while researching a future upgrade to the ATR Primary Coolant Pump (PCP) breakers/motor starters, an engineer noted that a control wire for the M-7 PCP was not properly attached to a terminal board in an electrical cabinet. The control wire is associated with the Low Inlet Pressure Loss of Coolant Accident (LOCA) PCP Shutoff System.

ATR TSR-186 LCO 3.2.3.3, LOCA PCP Shutoff System was not required to be operable at the time the wiring discrepancy was noted.

At 1654, Engineering informed Operations of the wiring discrepancy and determination was made that the situation was not reportable since the functional testing for this trip feature has performed satisfactorily. Upon further review, since the LOCA trip feature must be seismically qualified and the noted wiring discrepancy may impact the circuit's performance in a seismic event, the condition was 
determined to be a degradation of a Safety

Structure/System/Component; hence the discrepancy in discovery time and categorization.

\section{RAM Alarm on HFEF 2nd Level Causes Evacuation of 2nd Level}

NE-ID--BEA-HFEF-2014-0002 (Significance Category 3)

On July 31, 2014, while moving a loaded waste on the third

level of the Hot Fuel Examination Facility (HFEF), a Radiation

Area Monitor (RAM) alarmed in the second level of the HFEF.

The RAM alarm was not anticipated and resulted in a partial evacuation (second level) of the HFEF. The radiological dose from the loaded waste box on the third level was recognized and mitigated using appropriate measures and controls; however, the potential effect on the second level was not recognized nor controlled, resulting in the RAM alarm and partial evacuation of the HFEF. Based on dosimeter analysis, no detectible radiological exposure resulted from this event.

Due to Main Cell cleanout activities, radiation levels of the material being handled by the Waste Movement Crew have increased. The hazards analysis performed for the procedure being used for this activity did not analyze and provide mitigation for the higher radiation fields encountered during the movement of waste. The result of the change in hazards resulted in an unanticipated effect on collocated personnel working in areas adjacent to the waste movement activities. Personnel performing the waste box movement recognized that the radiation level of this box was significant and excluded personnel not associated with the box movement from the 3rd floor of the HFEF; however, personnel performing the waste box movement did not recognize that their work could/would impact personnel working on the 2 nd floor.

Lessons that can be learned from this event include the understanding that radiological hazard control and mitigation processes must be approached from a three dimensional perspective. Workers understood the radiological hazard from a two dimensional perspective and excluded/removed other workers that were not involved with the job from the third floor. Work on the second floor, where the ram alarmed, was considered to be unaffected by any work on the third floor, based on previous operational knowledge.

\section{Entry Into Limiting Conditions For Operation (LCO) Due to ATR Truck Airlock Door-441 Seal Depressurized} NE-ID--BEA-ATR-2014-0020 (Significance Category 3) On July 22, 2014, a small air leak was identified on the ATR Truck Airlock outer door, Door-441 (D-441). Increased surveillance on the door seal pressure and minimizing use of the door were both compensatory measures implemented to monitor and limit further seal damage. D-441 provides normal confinement boundary for the ATR building. ATR confinement is required during, and for, 30 minutes after, power operations, per ATR Technical Safety Requirements (TSR)-186. On August 12, 2014, at 1508, the alarm for D-441 seal pressure was received in the Reactor Control Room (RCR) indicating that the door seal had depressurized below the set point for the alarm due to the leak. The watch team entered TSR-186, LCO 3.8.1.A, which requires reactor shut down within 24 hours if the situation is not corrected. Steps to shut the inner truck airlock door, Door-15 (D-15), were started. At 1523, D-15 was shut, seal pressurized and associated ventilation dampers, $M-434$ and $M-435$, were shut to seal confinement. TSR-186, LCO-3.8.1.A was exited.

The cause of the event was determined to be an end-of-life failure of the door seal. The seal was replaced following the event.

\section{Fire Impairment Compensatory Measures LTA} NE-ID--BEA-MFC-2014-0004 (Significance Category 4) On August 12, 2014, Life Safety Services (LSS) personnel were performing a preventative maintenance (PM) on the fire system in buildings MFC-735 and -736. LSS notified the Alarm Center to inform the Alarm Center of their work in MFC-735 \& -736 and requested the Alarm Center to place account (zone) 901 into test mode to prevent activation of alarms that would require the MFC Fire Department to respond. At 1245, when the LSS technician tested an alarm in MFC-735, alarms in MFC-736 also activated. Additionally, the local alarm horns in MFC-710 activated, which caused personnel in MFC-710 to evacuate the facility. As a result of having account 901 in test mode, the MFC Fire Department did not receive notification to respond to the alarms in MFC-710. When the MFC Fire Department was informed by MFC personnel of the alarms in MFC-710, a call was placed to the Alarm Center and the MFC Fire Department was told that testing was being performed and not to respond. (NOTE: Account 901 covers 11 MFC facilities via one fire alarm panel.) When an account is placed into test mode, the alarm center does not monitor those buildings for alarms.

No compensatory measures were implemented via the fire impairment process to compensate for the nine buildings not covered under the PM work from a fire protection process. This event reinforces the fact that we need to think outside the box and consider the impact of the work on other facilities, not only the facility in which we are working. 


\section{Suspect/Counterfeit Bolts Encountered}

NE-ID--BEA-MFC-2014-0007 (Significance Category 4)

On August 13, 2014, Maintenance was preparing to perform

load testing on an overhead circuit breaker lift in MFC-752 (a non-nuclear facility) when the technicians observed that the bolts appeared to be suspect counterfeit bolts. The work was stopped and Quality Assurance (QA) was contacted. Upon QA inspection, they were deemed suspect counterfeit bolts. The bolts were removed and approved bolts were installed. Facility management was not notified of the event until November 14, 2014. Although this event was reported in ORPS in FY15, it is being included in this quarterly analysis because it occurred in FY14.

\section{Advanced Test Reactor (ATR) Confinement Leak Due to Hole in Floor Drain Pipe}

NE-ID--BEA-ATR-2014-0025 (Significance Category 4)

On September 15, 2014, an ATR Process Operator was in the motor floor area performing a work order planning walk down when he noticed water coming from a pipe that he knew was connected to the process restroom. Investigation revealed a custodian had just poured mop water down the floor drain located in the restroom. The Process Operator initiated a Maintenance Work Request (MWR) to report the issue, as he knew the drains from the restroom entered the ATR confinement. On September 16, 2014, further inspection of the drain pipe showed that the pipe hole was above the drain pipe P-trap and resulted in a leak from confinement. Confinement is required during, and for 30 minutes after, Power Operations, per ATR TSR-186. At the time of discovery, the ATR was in outage and defueled, so confinement was not required.

This leak had been previously identified and planned for repair. Originally the leak was not recognized as a leak around a confinement boundary.

\section{Loss of Immediate Facility or Offsite Emergency Response Capabilities}

NE-ID--BEA-SMC-2014-0002 (Significance Category 4)

The Private Branch Exchange (PBX) system, located at Test Area North (TAN) 601, went into a reset mode, causing a two to three minute loss of all telephone and fire alarm systems at TAN. All communications were restored once the system reset.

Proper notifications were made and Power Dispatch was asked to review performance data. Power Dispatch reported that there was no detection of a power dip or spike on their instrumentation.

\section{Other Non Reportable Events}

\section{SMC-CO-2014-1138}

On August 27, 2014, at approximately 0900, the flame detector on the Atmospheric Distribution System (ADS) Pad at the SMC, alarmed upon sensing a fire at the exit of the vent stack for the hydrogen storage tank. The ADS Pad contains storage tanks and distribution piping for hydrogen, nitrogen, and propane gases and is adjacent to TAN Building $679 / 679 \mathrm{~A}$, but is outside the physical boundaries of the SMC nuclear facility.

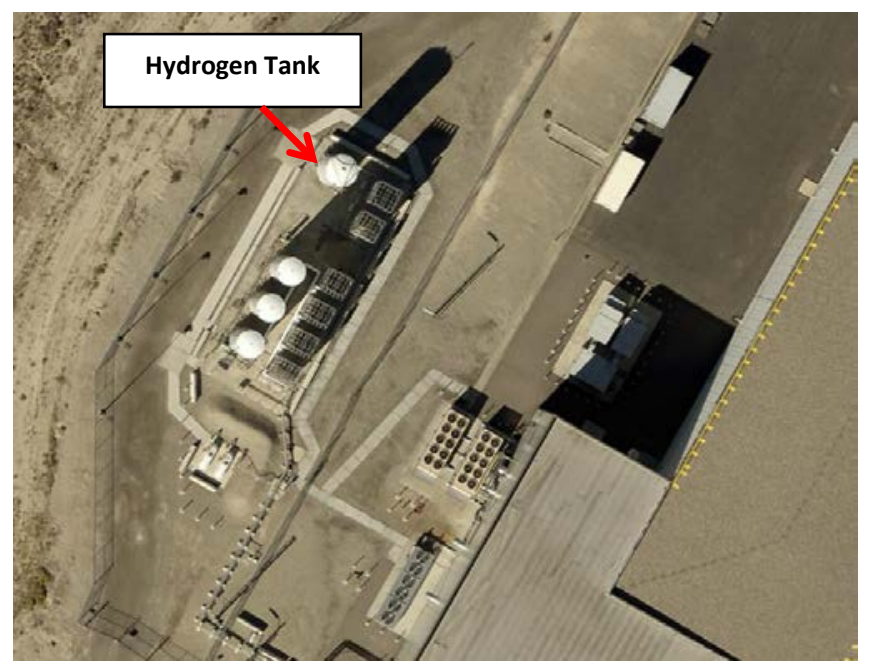

The tanks and piping themselves are owned by the gas vendor. A fire from the vent stack is an anticipated event with the response controlled by an SMC Abnormal Operating Procedure (AOP). The responsibility of extinguishing the fire falls upon the gas vendor; however, INL firefighters are available if help is needed. The INL Fire Department responded per that procedure, confirmed the location of the fire, and monitored the area. At 1100, the Fire Department returned to the station and preparations were under way to have the vendor assist in extinguishing the fire.

\section{CO-2014-3984}

On August 18, 2014, at IF-627, an overhead door was being operated by a worker when one of the "lifting" cables failed, causing the overhead door to drop approximately four feet to the ground.

Initial investigation has concluded the overhead door had bound up, causing the cable to stress and break. A recent (within the last three months) preventive maintenance work order was performed on this door, indicating the cable checked out as adequate for use. The worker was not injured as a result of the fallen door. 
As a result of this event, all INL roll-up doors were inspected for lifting cable degradation, rollers and tracks, and for proper opening and closing of the door. Any problems identified during the inspection were repaired or scheduled for repair.

\section{$4^{\text {th }}$ Qtr FY-14 GROUP 5 - ENVIRONMENTAL EVENTS}

\section{TREND SNAPSHOT}

Environmental Events: There was one environmental event reported in the $4^{\text {th }} Q \operatorname{tr} F Y-14$. The rate of occurrence of environmental events is trending slightly upwards, due to new 40 CFR, Part 63, Subpart ZZZZ (also known as Quad Z) requirements. Although the event reported this quarter is exact in nature to the environmental event reported the past three quarters, its occurrence is not indicative of an averse trend, but is the result of changes to 40 CFR Part 63.

When compared to the balance of the DOE complex, the percentage of occurrence of Group 5 environmental events at INL is higher than that of the balance of the DOE Complex and has increased since FY-13. All of the environmental events in FY-14 were related to 40 CFR Part 63, Subpart ZZZZ requirement changes.

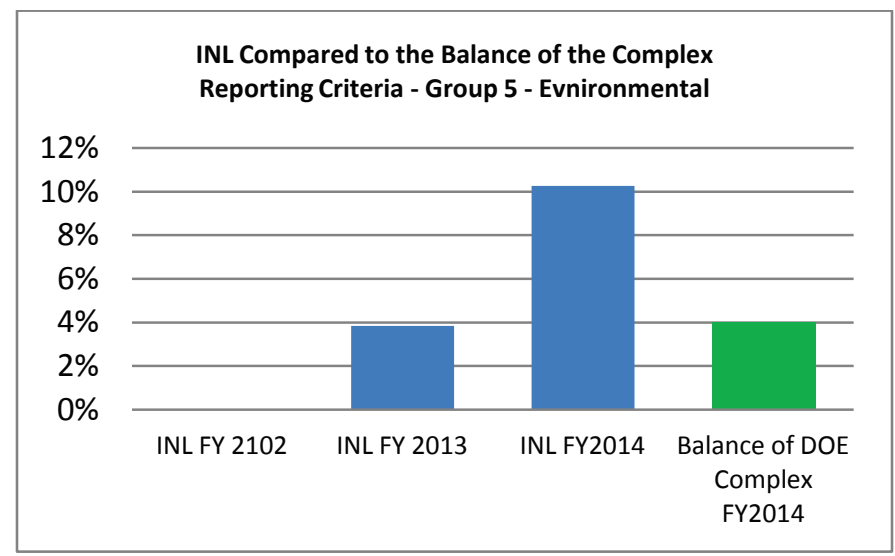

Events related to environmental problems are one of the least reported event types, accounting for only four events in the past 12 months one of which was reported in the $4^{\text {th }} \mathrm{Qtr}$ FY-14. This event is described in the following paragraph.

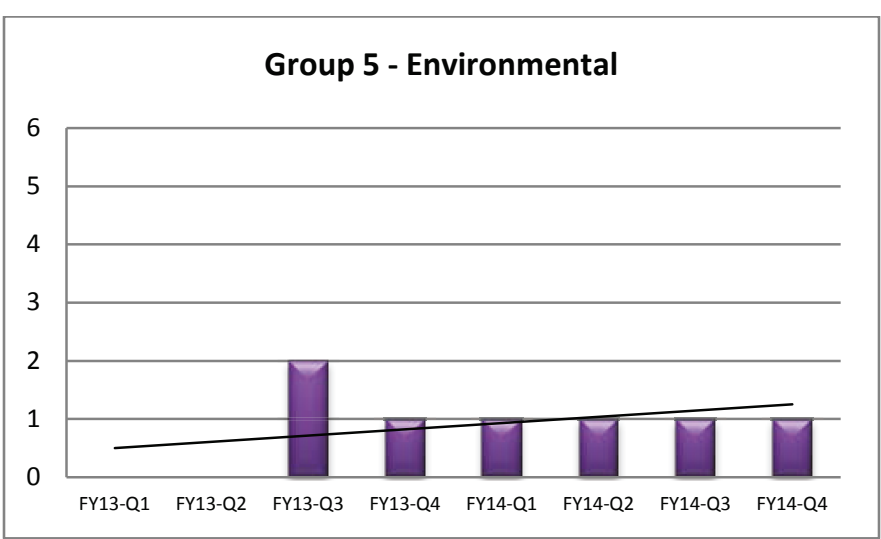

\section{Quarterly Report of Diesel Engine Startup at the Advanced Test Reactor (ATR)}

NE-ID--BEA-ATR-2014-0017 (Significance Category 4) New environmental regulations, operation, and maintenance requirements for ATR Complex diesel engines are in effect: 40 CFR, part 63, subpart ZZZZ, National Emissions Standards for Hazardous Air Pollutants for stationary reciprocating Internal Combustion Engines (RICE), also known as Quad Z.

The following ATR Complex engines are non-emergency stationary RICE: Generators 670-M-42, 670-M-43, and 674-M6. Without installation of emissions controls, units $670-\mathrm{M}-42$, 670-M-43, and 674-M-6 do not meet the new emission standards for hazardous air pollutants that went into effect on May 2, 2013. INL has negotiated with the Idaho Department of Environmental Quality (DEQ) a Voluntary Consent Order (VCO) to replace units 670-M-42 and 670-M43 with a commercial power based uninterruptible power 
supply (UPS). When the UPS project is complete in 2015, all three units will be designated as emergency stationary RICE.

\section{Other Non Reportable Events}

There were no additional non-reportable events related to environmental problems reported during the $4^{\text {th }} \mathrm{Q}$ tr FY-14.

\section{$4^{\text {th }}$ Qtr FY-14 GROUP 6 - CONTAMINATION/RADIATION CONTROL EVENTS}

\section{TREND SNAPSHOT}

Contamination/Radiation Events: There were no reportable events related to contamination/radiation control reported in the $4^{\text {th }} \mathrm{Qtr} F \mathrm{~F}-14$. The rate of occurrence of these types of events is trending slightly downwards over the past two years.

When compared to the balance of the DOE complex, $3 \%$ of the events reported at INL were reported under Group 6 Contamination/Radiation criteria; the balance of the DOE complex reported $5 \%$ of events under the same criteria. INL events reported in FY-12, included discovery of radioactive particles at ATR, and several events at MFC, including the plutonium contamination event in the Zero Power Physics Reactor (ZPPR). Since these events, added rigor to radiological work has paid off and is seen as a reduction in the number of radiological events.

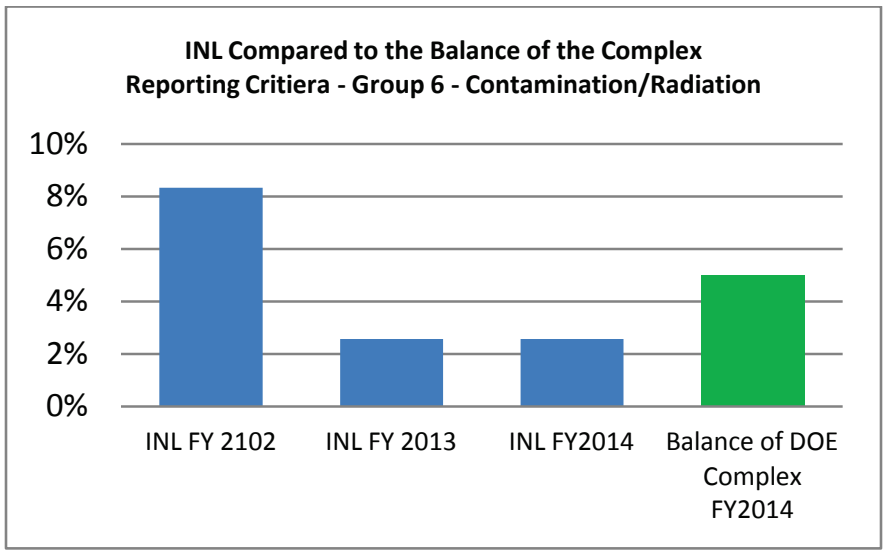

Events related to contamination and/or radiation control are some of the least reported event types at INL; these events have only accounted for one reportable event in the past 12 months. There were no reportable contamination/ radiation control events that occurred in the $4^{\text {th }}$ Qtr FY-14.

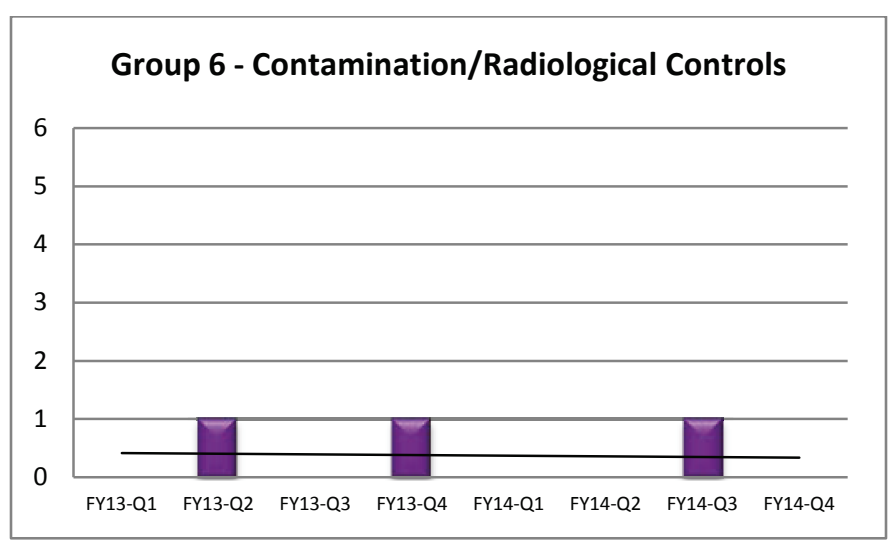

\section{Other Non-Reportable Events}

\section{CO-2014-3812}

During activities at the HFEF to obtain radiation readings from a waste container (5-Can) that was being lifted from the Decon Cell to the Hot Repair Area (HRA), higher than expected radiation readings were encountered.

During the survey, the radiation instrument being used to perform the radiation survey reportedly read off scale/high (in excess of $10,000 \mathrm{R} / \mathrm{hr}$ ). The radiation readings were being taken to conduct source term calculations in preparation for disposal of the waste.

Two buildings that are located near HFEF reported elevated background radiation fields during the time-frame the 5-Can was being moved to perform the radiation readings. Some issues that were brought to light during a fact finding meeting include: unexpected/unmonitored potential radiation exposure to personnel outside of HFEF; using an incorrect procedure for the work evolution; RAM audible alarms were bypassed without procedure guidance; decontamination cell 
background radiation was believed to be too high to obtain readings; and the decontamination cell radiation instrument was not calibrated at the time of the event. A lack of procedural control was found to be the cause of the event.

\section{$4^{\text {th }}$ Qtr FY-14 GROUP 7 - NUCLEAR EXPLOSIVE SAFETY EVENTS}

There were no events related to nuclear explosive safety during the $4^{\text {th }}$ quarter FY-14. BEA has never reported an event under this reporting criterion since taking over the contract for the INL in 2005. Across the DOE complex, there were five nuclear explosive safety events reported in FY-14.

\section{$4^{\text {th }}$ Qtr FY-14 GROUP 8 - PACKAGING AND TRANSPORTATION EVENTS}

\section{TREND SNAPSHOT}

Packaging/Transportation Events: There were no packaging and transportation events reported during the $4^{\text {th }} \mathrm{Qtr}$ FY-14. The two year trend data for these types of events shows a very slight increasing trend because of the one event reported during the $1^{\text {st }}$ Qtr FY-14.

INL events reported under Group 8 Packaging and Transportation criteria were consistent with those reported across the balance of the DOE Complex. The only INL event that occurred in FY-14 was related to the discovery of an unsecured drum in an exclusive use container when the container arrived at its destination.

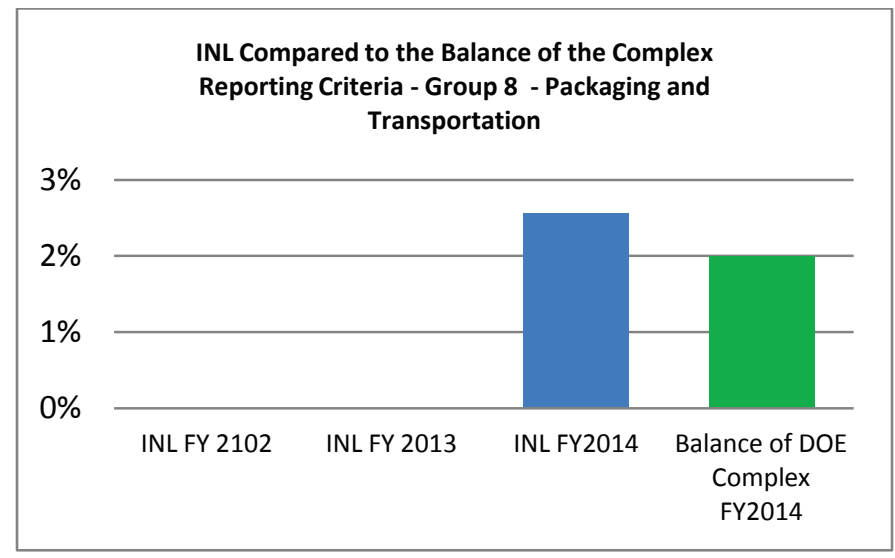

Events related to packaging and transportation rarely occur at INL; there has been one such event in the last two years. No packaging and transportation events were reported during the $4^{\text {th }}$ Qtr FY-14.

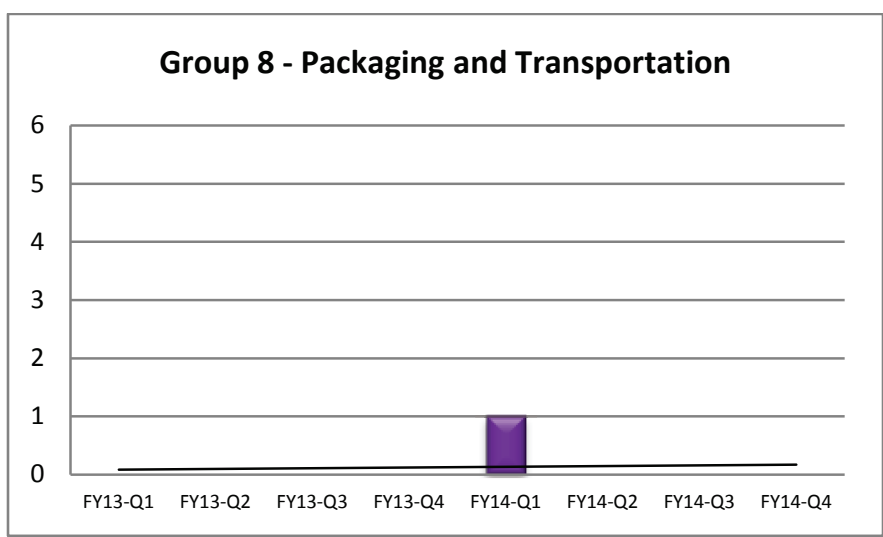




\section{TREND SNAPSHOT}

Packaging/Transportation Events: Noncompliance notification events are reported when the INL receives written notification from an outside regulatory agency that the site or an INL facility is considered to be in noncompliance with a schedule or requirement. Over the past 12 months, the INL has issued two noncompliance notifications and have reported them through ORPS. Both of these were reported during the $4^{\text {th }} \mathrm{Qtr} F Y-14$. The two year trend data for these types of events shows an increasing trend because of the recent events.

INL events reported under Group 9 Noncompliance Notifications were consistent with those reported across the balance of the DOE Complex. The only two events reported in FY-14 were reported this quarter and are summarized below.
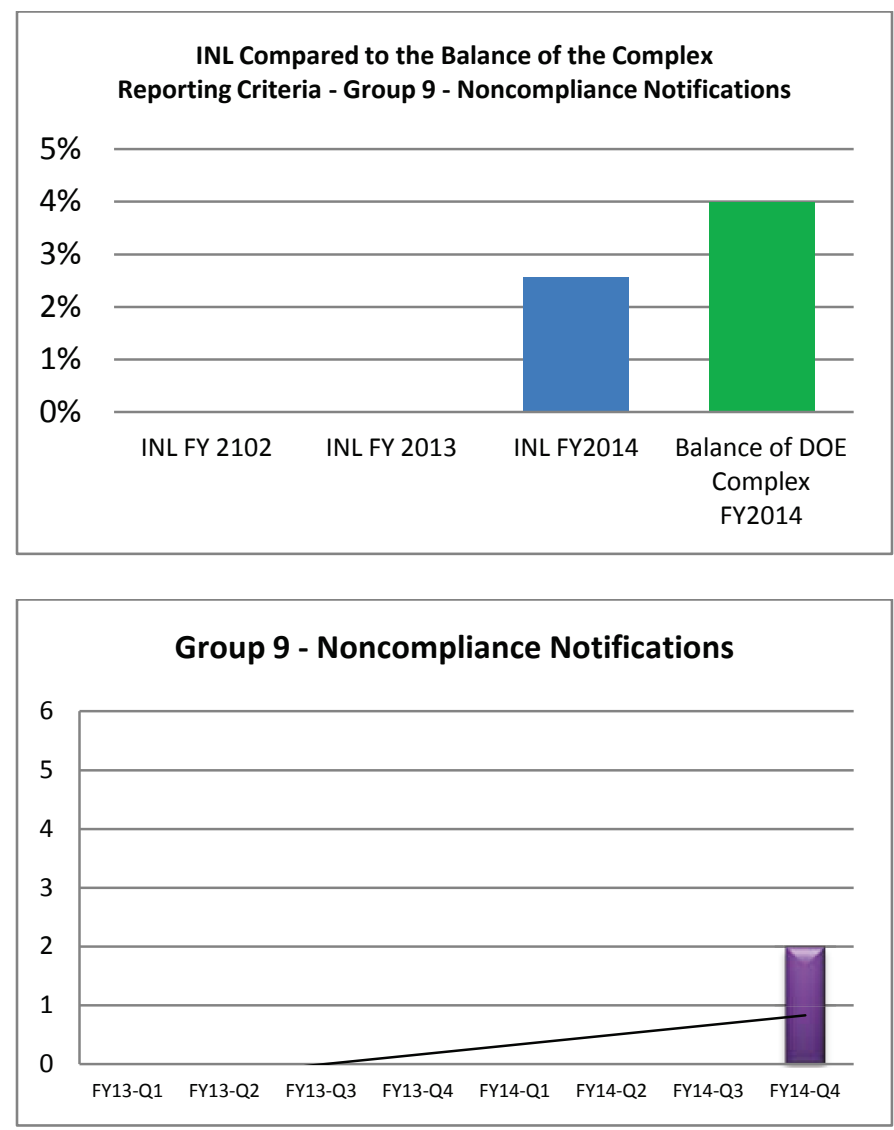

\section{Failure to Report Modifications to a RCRA Permitted Unit}

NE-ID--BEA-TSD-2014-0001 (Significance Category 4)

From March 6, 2014 through March 25, 2014, a new wall with no openings was constructed between the West Room and the East Room at the Experimental Fuels Facility (EFF).The existing wall had a roll-up door and a man door between the two rooms. The EFF west side was converted to lab space for producing extruded fuel pins in support of the Terra Power project with construction, beginning in September 2013, and completing in August 2014. In December 2013, it was determined that the EFF west side needed to be a separate fissile material balance area (MBA) from the EFF east side. In order to do this, a 14 inch separation wall was constructed from March 6, 2014 through March 25, 2014, blocking both the roll-up door and the man-door between the west and east side of EFF. EFF is a permitted facility for storage of Resource Conservation and Recovery Act (RCRA) waste, however, no RCRA waste is currently stored there.

Battelle Energy Alliance (BEA) failed to provide notice to the DEQ Director of planned changes to the EFF and failed to complete a permit modification to address changes to EFF.

On April 28, 2014 through May 1, 2014, DEQ performed an inspection at EFF and noted the modifications to the EFF. On September 18, 2014, BEA received a Notice of Violation from DEQ for failure to notify the DEQ Director of the planned changes and failure to submit a permit modification.

A briefing was held with management and environmental personnel and it was determined that EFF was in a safe configuration with no other immediate actions needed.

Although EFF did not contain RCRA hazardous waste at the time of the modifications, it was still a permitted facility. Personnel must be aware that any changes to permitted facilities require careful review against requirements. 


\section{Inadequacies in Underground Storage Tanks}

NE-ID--BEA-CFA-2014-0003 (Significance Category 4)

On August 27, 2014, an inspection of the underground storage tanks (USTs) at INL was performed by DEQ. There were several inadequacies identified and were documented in an email received on August 29, 2014. The email communicated ten informal warnings and one formal warning issued. F\&SS personnel began to evaluate areas to determine what corrections had already been completed and what needed to be planned.

\section{$3^{\text {rd }}$ Qtr FY-14 GROUP 10 - MANAGEMENT CONCERNS AND ISSUES}

\section{TREND SNAPSHOT}

Management Concerns and Issues: Three events were reported in the $4^{\text {th }}$ Qtr FY- 14 under reporting critiera for a management concern or issue. The number of management concerns increased from last quarter and the rate of occurrence is trending slightly downward over the past 12 months.

The past three quarters has seen a steady decline in events reported under these criteria. Events reported as management concerns or issues accounted for $13 \%$ of the events reported over the past 12 months. Three events were reported during the $4^{\text {th }}$ Qtr FY14; they are summarized below.

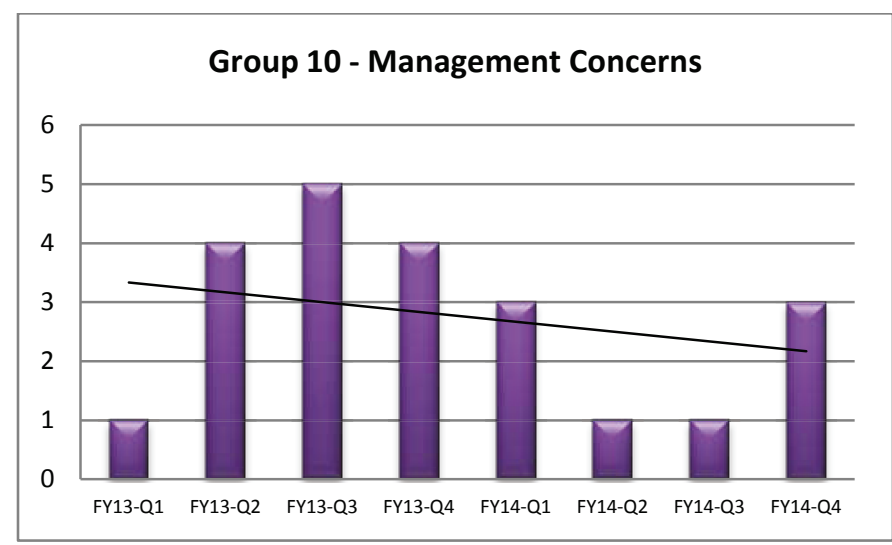

\section{Experiment Loop 2E-NW Pressurizer Heater Leg Piping}

\section{Leak at the ATR}

NE-ID--BEA-ATR-2014-0024 (Significance Category 4)

At August 30, 2014, an elevated leak rate was noted by the on-watch Experiment Operator at the ATR. The initial leak investigation, performed with the loop at temperature and pressure, determined that the leak was likely caused by pressurizer vent valves leaking by the seats of the valves. Due to the high leak rate, the decision was made to shut down the reactor and cool down experiment loop 2E-NW. At 0242, a manual reactor scram was performed.
Later that day, following loop and pressurizer cool down, the primary cubicle for loop 2E-NW was entered and it was discovered that the actual source of the leak was a through wall crack on one of the pressurizer heater leg pipes. The $2 \mathrm{E}-$ NW pressurizer has five 3-inch pipe arrangements that provide a location for heater castings to be banded to the pipes. The leak is located on a lower horizontal section of one of the heater legs. The leak is located in an inaccessible area during loop and reactor operation and did not present an immediate risk to operating personnel. The manual scram was performed as a precautionary action prior to reaching the abnormal procedure mandated scram action point.

An engineering evaluation of this material failure is in progress to determine a path forward. An Extent of Conditions will also be performed on heater leg piping with like material, Loops 2E and 2D specifically. Based on the results of the exams, a plan to inspect other experiment loop pressurizer piping will be determined. 


\section{Alpha Contamination Outside of a Hood}

NE-ID--BEA-AL-2014-0004 (Significance Category 3)

Researchers have been developing a method for alpha spectroscopy in the AL for the past several months. Part of that work is the use of a Pu-238 standard to develop a baseline for the instrumentation. An existing $2007 \mathrm{Pu}-238$ standard (a five gram solution of 8 molar nitric acid with 100 micro curies of $\mathrm{Pu}$-238) was identified for use in relation to this project. The standard was sealed in the original glass vvial with a plastic screw cap, wrapped with parafilm, and then taped. The glass v-vial was stored inside of a plastic container with a snap-cap lid. The standard had been stored in a fume hood in Room B-154 until September 9, 2014, when it was retrieved in preparation for alpha spectroscopy.

On September 16, 2014, during performance of routine surveys in the $\mathrm{AL}$, a smear survey showed High Contamination Area (HCA) levels of alpha contamination. All personnel in the potentially affected areas were removed and surveyed out of the facility.

The Health Physics Technician (HPT) immediately notified the personnel in the area and contacted additional Health Physics (HP) support. Management was notified. The area was cleared and the smear was submitted for alpha spectroscopy. The alpha spectroscopy results on the HCA smear showed 23 dps alpha for Pu-238. Thorough surveys of all adjacent areas were performed with no additional contamination found.

Further surveys are underway to determine the potential origination of the contamination and any potential exposures. Nasal swabs were collected from three workers (two researchers and one HPT), that had performed work within hoods in B-111 and B-119. Initial results indicated that one worker had nasal counts of $4 \mathrm{dpm}$, which is greater than 0 but less than the minimum detectable activity (MDA) for the instrument. Follow-up counts on the nasal smears showed a decrease in activity, which is a likely indication of radon. All three workers received lung counts with no plutonium activity detected and bioassay was started.

An analysis of the event found that accepted radiological control practices were not sufficiently conservative to minimize the potential spread of contamination.

Additionally, INL process could have been more conservative in defining confinement requirements and specific direction was not provided for use of various radiological risk mitigations as a graded approach based on potential hazards.
Finally, RWP survey requirements were not followed by the researcher and a time-out was not used when unusual conditions (cap degradation) were encountered. Evaluation of the decision process for the types of work allowed on a bench top or in a fume hood and evaluation of waste handling practices is being performed.

\section{MFC-704 FMF Suspect Contamination Found on CAM Filters}

NE-ID--BEA-FMF-2014-0001 (Significance Category 3) On September 24, 2014 (approximately 1400), an MFC Radiological Engineer informed the Secure Facilities Nuclear Facility Manager (NFM) of an analysis report indicating possible higher than normal activity air borne radioactivity levels in the Advanced-Fuel Cycle Initiative ( $\mathrm{AFCl}$ ) enclosure (room) within the Fuel Manufacturing Facility (FMF) (MFC704 FMF).

Low levels of transuranic contamination were detected on (4) separate filters taken from the area fixed Continuous Air Monitor (CAM) and Portable Low Volume Air Sampler. The detectable amounts were less than the CAM alarm set point (8 DAC) but greater than the limit for establishing an airborne radioactivity area (ARA greater than 0.3 DAC).

There were no high level CAM activity alarms in this area. At all times, there has been a functional CAM and portable air sampler which was being used in lieu of the Fixed Air Sampling System (FASS) which was undergoing maintenance during facility occupation and glovebox activities. The reported results from the analysis indicated greater than 0.02 DAC (which is the threshold at which Radiological Engineering investigates filter activity), but less than 8 DAC (alarm set point). DAC is the standard unit for Derived Air Concentration.

The $\mathrm{AFCl}$ enclosure in $\mathrm{FMF}$ contains two interconnected transuranic glove boxes with a mission to support Fuel Cycle Research and Development (FCRD) at the MFC at INL. Processing activities conducted in the $\mathrm{AFCl}$ glovebox during this period of time, include characterization sample fabrication using the arc-melting process and transuranic material breakout. Additionally, distillation of americium has been performed in this glovebox within the past six months.

A test plan has been developed to identify and/or troubleshoot the source of the contamination. It is anticipated this analysis will be completed during the first quarter FY-15. 


\section{Other Non-Reportable Events}

There were no additional non-reportable conditions that are being addressed as management concerns.

\section{$4^{\text {th }}$ Qtr FY-14 EVENTS INVOLVING SUBCONTRACTORS}

\section{TREND SNAPSHOT}

Events Involving Subcontractors: One events involving subcontract employees occurred during the $4^{\text {th }} \mathrm{Qtr} F Y-14$. The number of reportable occurrences involving subcontractors continues to trend downwards over the last two years. There are no noted trends (e.g., causes, subcontractor involved, etc.) associated with events involving subconract personnel.

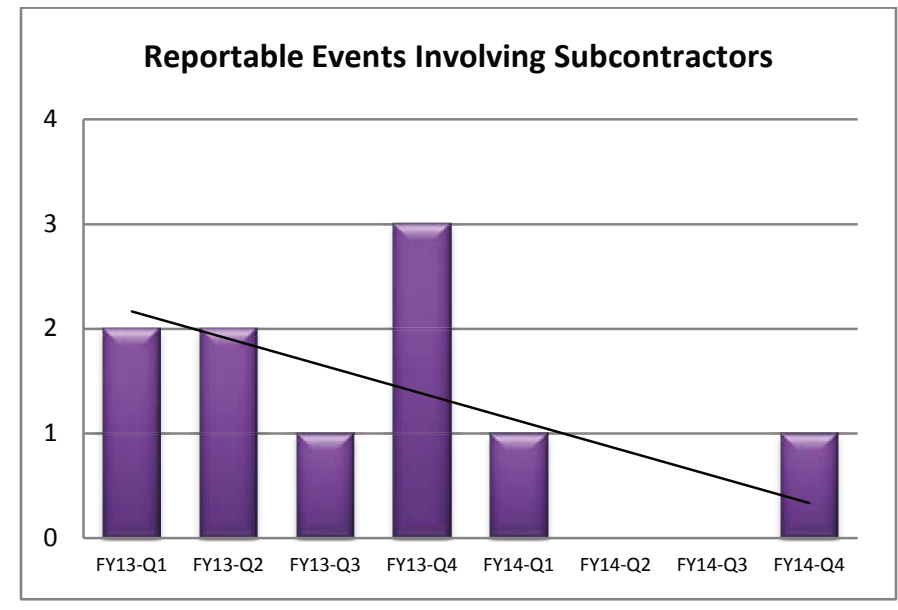

There have been ten ORPS reportable events involving subcontractors during the past two years; one was reported during the $4^{\text {th }}$ Qtr FY-14. The $4^{\text {th }}$ Qtr FY-14 event has been included under the Group 2 - Personnel Safety and Health section of this report and involved the lockout tagout on the Plasma Hearth Project.

\section{$4^{\text {th }}$ Qtr FY-14 ANALYSIS OF CAUSES OF REPORTABLE EVENTS}

Cause analysis results documented in ORPS were analyzed to determine trends, within the causes identified, over the past two years and during the past 12 months. The analysis shows that the majority of causes over both time periods can be attributed to human performance, management, and communications.

Over the past twelve months, human performance problems were equally reported as skill, rule, and knowledge based errors. However, a decline (6\%) in the percentage of causes related to human performance and management problems ( $7 \%$ decline) is indicative of successful mentoring and oversight achieved by having management spend time in the field, watching work and addressing incorrect behaviors before they lead to events.

An increase in discovery of problems associated with design and engineering, as well as equipment and material problems shows that equipment problems are finding us instead of us finding problems with equipment.

The chart below shows the trending of reportable events by cause code. An additional chart has been added to this quarterly analysis that shows those events (other than Significance Category 4 events) that were related to 
equipment problems, and those that were related to human performance issues. This data will be monitored and action taken if any trends are noted.

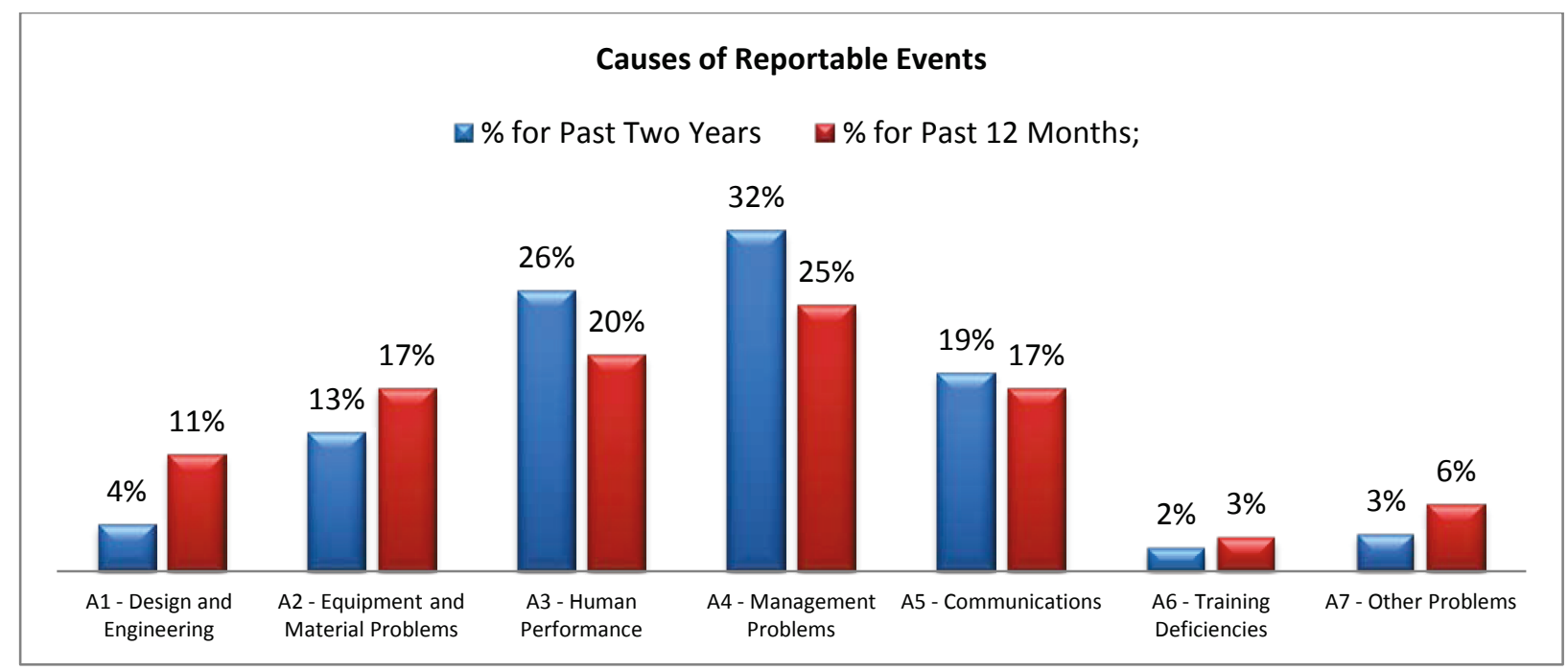

In addition to evaluating events for cause, INL analyzes each reportable event to identify where we failed to effectively implement the five ISMS core functions. The chart on the next page shows the Significance Category $O E, R, 1,2$, and 3 events that occurred at INL and their corresponding ISMS core function failures.

The majority of failures were identified with execution of Core Function 4 - Perform Work within Controls. To address this, INL included procedure compliance as a key topic in continuing Conduct of Operations training held throughout FY2014. In addition, INL has taken an initiative to enhance the Management Observation Program.
The management observation program enables safe, secure, efficient and effective work performance through regular, purposeful, and documented management presence where and when employees perform work. This is achieved by management personally observing work activities and communicating with employees to solicit input and provide mentoring, coaching, and timely feedback on behaviors. This program strengthens application of Core Function 4 by ensuring personnel are performing work in accordance to procedures and work control documents. 


\section{FY-2014 Operational Events}
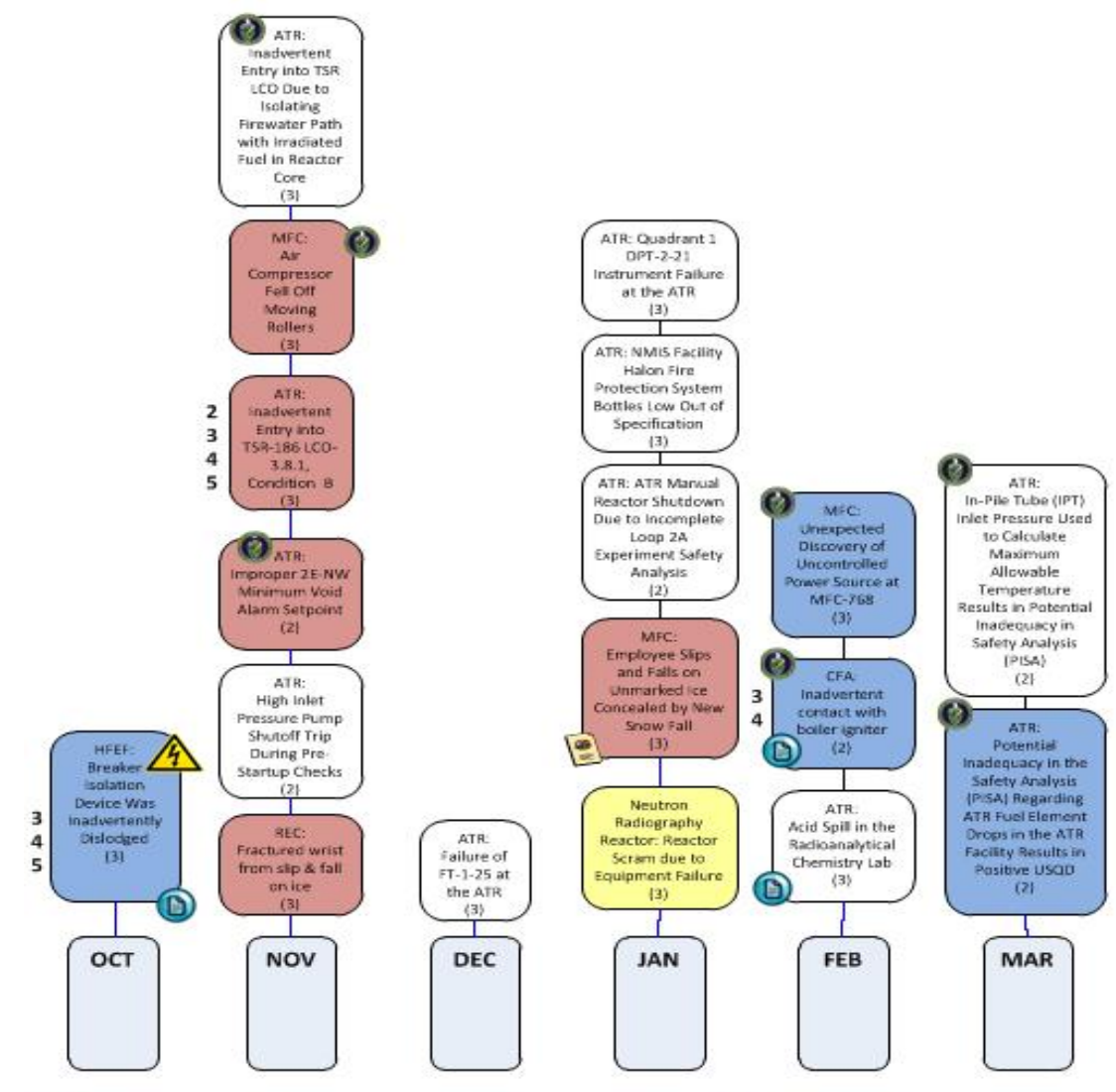

(1) NIS (19)

8 Radiological $\widehat{A}$ Electrical
(\$) Fee Reduction
Primary isms Core Funstion Failure Colos Lenend Defire the scope or work Developplimplement Controls
Peflorm Wurk wifin Controly

Any additionat I SMMS codes

the cause analysis are istersed to to the leff of of the

NIS (1) Formal Lessons Leamed

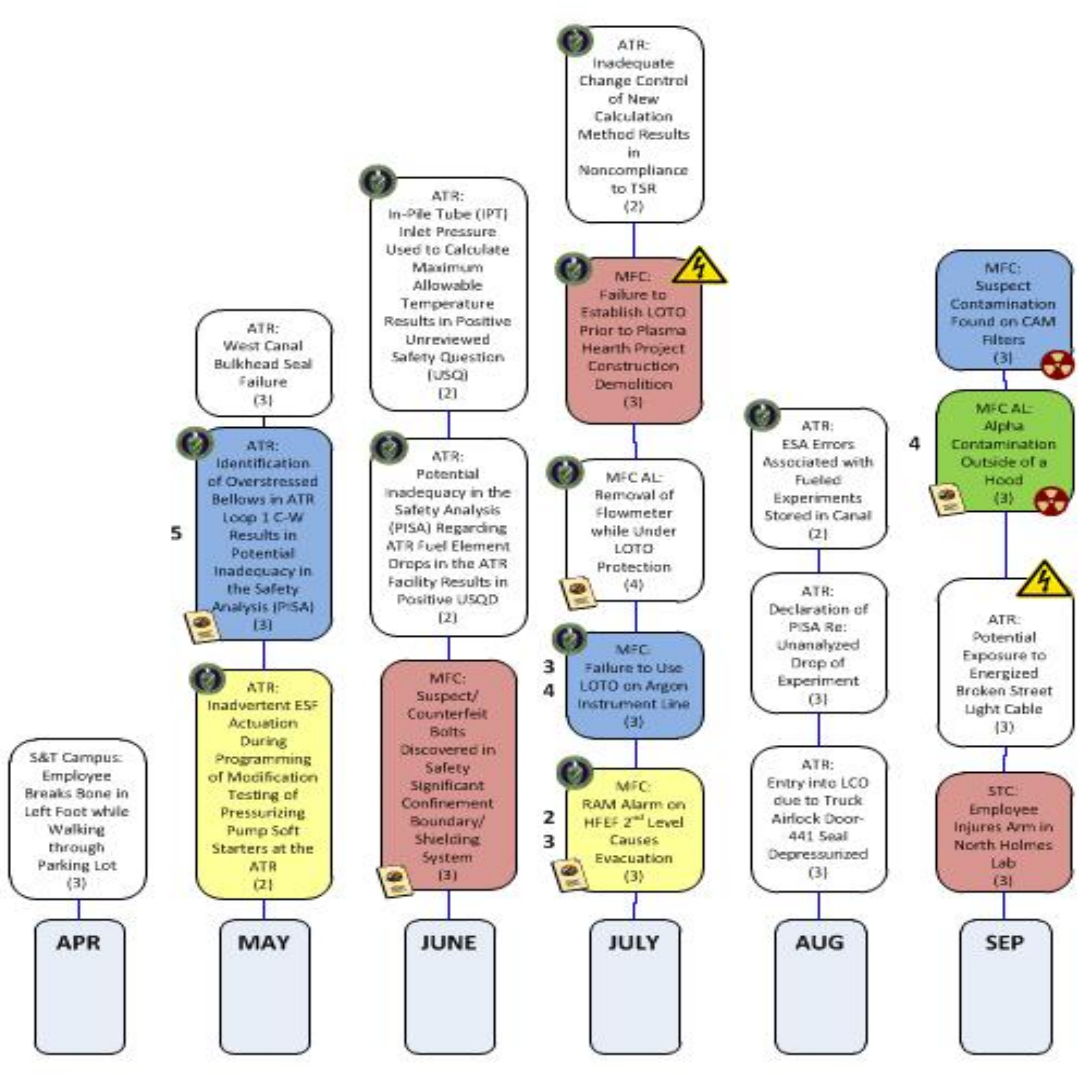

1 Page Lessons Learned

(H) ORPS Significance Category Level 


\section{TREND SNAPSHOT}

IOPAC Trending Analysis: For the $4^{\text {th }}$ Qtr FY-14, the eight mission centers [ATR, MFC, SMC, National and Homeland Security (N\&HS), Nuclear S\&T (NS\&T), EES\&T, F\&SS, and Laboratory Protection (LP)] continued to evaluate ORPS events, INRs, and LabWay issues for trending. In addition, analysis from the Radiological Controls Management System, the INL Work Management System, and Conduct of Operations were also presented by the Integrate Operations Performance Analysis Committee (IOPAC) to INL Senior Management. Issues common across the INL and issues that continue to affect the INL are summarized below.

In addition to the IOPAC, a Nuclear Safety Culture Monitoring Panel met to review emergent issues that could impact nuclear safety culture health and to ensure issues are addressed appropriately. The panel will meet quarterly to assess nuclear safety culture trends or potential issues. The NSCMP and IOPAC found similar problems including:

- There have been 75 condition reports generated by DOE inspections in $\mathrm{CY}-14$. Forty-six were documenting concerns with work processes and 13 with personnel accountability - primarily procedure adherence.

- $55 \%$ of conditions are coded as work process issues. Further breakdown shows the problems in documentation, specifically, procedure problems, drawing errors, or incorrect work instructions.

- Personnel accountability was also ranked among the higher reported safety culture traits.
- Improvements in implementation of conduct of operations principles are being noted across the laboratory.

- $\quad$ There is a need for increased management field presence.

- Legacy issues (those older than 200 days) need to be reviewed and validated for continued action.

- Personnel are stopping work when procedures are found to be incorrect or unclear.

To address these concerns, teams have been established to streamline work processes and simplify the change management process.

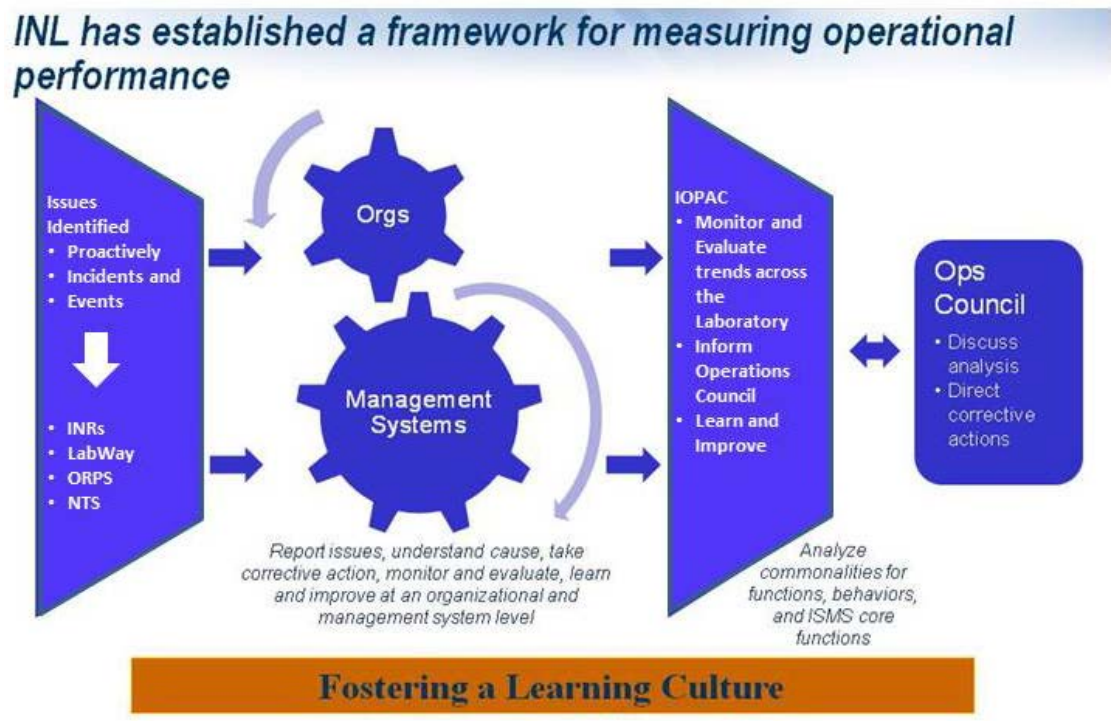

Figure 1. Framework for Measuring Operational Performance 


\section{INL Quality and Performance Management Expectations}

The INL mission involves performing and deploying world class research that meets the nation's needs in the areas of nuclear energy, other energy, the environment, and national security. Quality and Performance Management plays a critical role in supporting the INL mission. Our mission is to:

- Ensure we as a Lab know how we are doing and are improving our performance.

- Own and manage the Laboratory Issues Management System.

- Provide high quality QA program support for research and operations.

- Provide effective independent oversight.

"In order to be successful, we must be leaders, we must be competent, and we must be accountable. We must also exhibit the INL values of excellence, integrity, ownership, and teamwork." - Chris Hott, Director-INL Quality and Performance Management

Idaho National Laboratory

INL Quality and Performance Management

P. O. Box 1625, Mail Stop 3206

Idaho Falls, ID 83415

INL/EXT-14-33707 